\title{
The FOXG1/FOXO/SMAD network balances proliferation and differentiation of cortical progenitors and activates $K c n h 3$ expression in mature neurons
}

\author{
Riccardo Vezzali ${ }^{1,2}$, Stefan Christopher Weise ${ }^{1,2}$, Nicole Hellbach ${ }^{1}$, Venissa \\ Machado $^{1}$, Stefanie Heidrich ${ }^{1}$ and Tanja Vogel ${ }^{1}$ \\ ${ }^{1}$ Department of Molecular Embryology, Institute of Anatomy and Cell Biology, Faculty of Medicine, University of Freiburg, \\ Freiburg, Germany \\ ${ }^{2}$ Faculty of Biology, University of Freiburg, Freiburg, Germany \\ Correspondence to: Tanja Vogel, email: tanja.vogel@anat.uni-freiburg.de
}

Keywords: TGFß; neurogenesis; transcriptional control; cerebral cortex; atypical Rett syndrome; Gerotarget

Received: November 19, $2015 \quad$ Accepted: May 11,2016

Published: May 21, 2016

\section{ABSTRACT}

Transforming growth factor $\beta$ (TGF $\beta$ )-mediated anti-proliferative and differentiating effects promote neuronal differentiation during embryonic central nervous system development. TGF $\beta$ downstream signals, composed of activated SMAD2/3, SMAD4 and a FOXO family member, promote the expression of cyclindependent kinase inhibitor Cdkn1a. In early CNS development, IGF1/PI3K signaling and the transcription factor FOXG1 inhibit FOXO- and TGF $\beta$-mediated Cdkn1a transcription. FOXG1 prevents cell cycle exit by binding to the SMAD/FOXO-protein complex. In this study we provide further details on the FOXG1/FOXO/SMAD transcription factor network. We identified ligands of the TGF $\beta$ - and IGF-family, Foxo1, Foxo3 and $K c n h 3$ as novel FOXG1-target genes during telencephalic development and showed that FOXG1 interferes with Foxo1 and Tgf $\beta$ transcription. Our data specify that FOXO1 activates Cdkn1a transcription. This process is under control of the IGF1pathway, as Cdkn1a transcription increases when IGF1-signaling is pharmacologically inhibited. However, overexpression of CDKN1A and knockdown of Foxo1 and Foxo3 is not sufficient for neuronal differentiation, which is probably instructed by TGF $\beta$ signaling. In mature neurons, FOXG1 activates transcription of the seizure-related Kcnh3, which might be a FOXG1-target gene involved in the FOXG1 syndrome pathology.

\section{INTRODUCTION}

During neuronal differentiation progenitor cells are instructed according to a precise spatial and temporal plan, and specific signals control the equilibrium between proliferation and differentiation. Among these signals are extrinsic cues such as growth factors or activators of intracellular signaling pathways. Since proliferation and differentiation take place simultaneously in developing organ systems, cellular interpretation of such signals has to occur cell autonomously, for example through activity of specific transcription factors. Transforming growth factor $\beta$ (TGF $\beta$ ) is an extrinsic cue implicated in neuronal differentiation of cortical progenitor cells
(CPCs) $[1,2]$. It has 3 different isoforms (TGFB1, 2, and 3 ) and is a member of the TGF $\beta$ superfamily, including Bone morphogenetic proteins (BMPs) and Activins. Canonical TGF $\beta$-signaling occurs via SMAD-dependent pathways, in which the receptor complex phosphorylates R-SMAD (SMA- and MAD-related protein) 2 and/or 3. Phosphorylated SMAD2 and 3 translocate to the nucleus together with SMAD4 [3]. SMAD proteins bind to diverse cofactors. SMAD/cofactor complexes activate or inhibit context-dependent transcription of a variety of target genes, which is apparent through the diversity of processes controlled by TGF $\beta$ [4-6].

During embryonic neurogenesis, TGF $\beta$ exerts antiproliferative and differentiating effects on neuronal 
progenitor cells $[1,7,8]$. TGF $\beta$-signals lead to cell cycle arrest in G1 phase by transcriptional activation of the cyclin-dependent kinase inhibitors $C d k n 1 a$ and $C d k n 2 b$, as well as repression of the myelocytomatosis oncogene (cMyc) and inhibitor of DNA binding 1, 2 and 3 (Id1-Id3) [9-11]. Forkhead box O (FOXO) proteins are cofactors of SMAD3 and SMAD4 in the TGF $\beta$-induced formation of a Cdkn1a-activation complex [7]. FOXO proteins are important in the control of cell and organismal growth, development, metabolism and longevity. The phosphatidyl inositol 3-kinase (PI3K) growth-promoting pathway negatively controls FOXO factors through thymoma viral proto-oncogene (AKT)-mediated phosphorylation of FOXO proteins, which prevents their translocation to the nucleus [12].

Another FOX family member, FOXG1, opposes the activity of SMAD/FOXO-complexes by preventing transcriptional activation of Cdknla through a noncompetitive, direct binding of $\mathrm{FOXO} 3$ in the $\mathrm{FOXO} /$ SMAD complex [7, 13]. Absence of FOXG1 during mouse embryonic development leads to death at birth due to hypoplasia of cerebral hemispheres [14]. In CPCs it promotes self-renewal of neural precursors and antagonizes neuronal differentiation [14-17]. FOXG1 expression is dynamic during cortical development whereby it is transiently downregulated when progenitors enter neuronal differentiation. The re-expression of FOXG1 in differentiating neurons is necessary for correct integration into the cortical plate [18]. The interference of FOXG1 with TGF $\beta$ - and FOXO-mediated cell cycle exit might be responsible for its inhibition of neuronal differentiation. However, as the biochemical data that described the role of the FOXG1/FOXO/SMAD transcriptional complex in Cdknla expression comes from keratinocytes [7], this notion has still to be proven in CPCs. Regulation of Cdknla expression by TGF $\beta$, FOXO3 and FOXG1 might also be important for the differentiation of Cajal-Retzius (CR) neurons [19]. CR cells are among the earliest born neurons in the developing cerebral cortex [20-22] and are generated from different telencephalic regions, some of which do not express FOXG1 [23, 24].

Despite a substantial body of data, the functional role of the FOXG1/FOXO/SMAD transcription factor network in the cerebral cortex is mostly correlative $[8,19$, 25] and several open questions remain. Firstly, FOXG1 and FOXO proteins might be a node of intersection between TGF $\beta$ - and IGF-signaling pathways. In contrast to this view, we recently reported that IGF1-signaling activates cell proliferation in early cortical development (E13.5), whereas TGF $\beta$-signaling is mainly active at later stages (E16.5) [2]. Hence, FOXG1 and FOXO proteins might be cofactors that are implicated in different developmental responses to IGF1- and TGF $\beta$-signals rather than nodes of intersection. Secondly, it is unclear whether expression of Cdknla or FOXO proteins is sufficient to stimulate neuronal differentiation. Thirdly, further target genes apart from Cdknla in CPCs or in mature neurons might be controlled by FOXG1/FOXO/ SMAD transcription factors. Hence, we studied the FOXG1/FOXO/SMAD network in CPCs of different developmental stages and in different mouse models. Our analyses revealed that (1) FOXG1 impaired TGF $\beta$-induced neuronal differentiation in early developmental stages, i.e. E13.5; (2) FOXG1 blocks transcription of Cdknla, Tgf $\beta$, Foxol and Foxo3; (3) expression of Cdknla is activated by FOXO1; (4) neither CDKN1A, FOXO1 or FOXO3 can stimulate neuronal differentiation autonomously; and (5) Kcnh3 is a novel neuronal FOXG1-regulated target gene which might be of clinical relevance in atypical Rett syndrome.

\section{RESULTS}

\section{FOXG1 antagonizes TGF $\beta$-mediated neuronal differentiation at early developmental stages}

In vitro cultivated CPCs from E16.5 mouse cerebral cortex differentiate upon a TGF $\beta$ stimulus, but this instructive effect is not observed in E13.5-derived cells $[1,2]$. FOXG1 has the ability to prevent premature differentiation [16] and it antagonizes the TGF $\beta$-pathway by inhibiting $C d k n l a$ transcription through association with the FOXO/SMAD4 complex, at least in keratinocytes [7]. Based on these observations, we hypothesized that altered expression levels of FOXG1 could be causative for the differences in responsiveness to TGF $\beta$ of E13.5 and E16.5-derived CPCs. Although FOXG1 has been studied to some extent, FOXG1 mRNA and protein expression during development has not yet been reported. We assessed FOXG1 expression in the telencephalon in vivo using reverse transcription-quantitative real-time PCR (qRTPCR) (Figure 1A), immunoblotting (Figure 1B, 1C) and immunohistochemistry (Figure 1D) at different developmental stages. On the transcriptional level, Foxg1 expression increased significantly after E11.5 and remained on similar levels until the adult stage, where it declined significantly compared to embryonic stage E17.5 (Figure 1A). Expression changes on the protein level were slightly shifted to the later stage and the highest amounts of FOXG1 were identified in E16.5, E17.5 and E18.5 (Figure 1B, 1C). In the adult, less protein was detected in the lateral cortex (LC) and hippocampus (Hippo) compared to embryonic telencephalon of different stages. Immunohistochemistry of FOXG1 in forebrain sections of E11.5, E13.5 and E16.5 indicated that FOXG1 was expressed predominantly in progenitor cells at E11.5, whereas E13.5 forebrains expressed FOXG1 in progenitor cells and mature neurons. At E16.5 FOXG1 expression is confined mainly to mature neurons (Figure 1D). Together, 
these data indicated that the expression of FOXG1 is dynamic during development. FOXG1 expression thereby increased from E11.5 onwards, and coincided with increasing numbers of postmitotic neurons in the cortical plate. Hence, FOXG1 could indeed antagonize TGF $\beta$ mediated neurogenesis during early development at E11.5 and E13.5. On the other hand, reduced levels of FOXG1 in
E16.5 progenitor cells might render progenitors responsive to differentiative TGF $\beta$-signals. Our recent reports on TGF $\beta$-mediated neuronal differentiation are based on a culture paradigm where E13.5- and E16.5-derived cortical cells were cultured until day in vitro (DIV) 8 [2]. We therefore hypothesized that FOXG1 expression in CPCs might decline between E13.5 and E16.5 in vitro. We thus
A

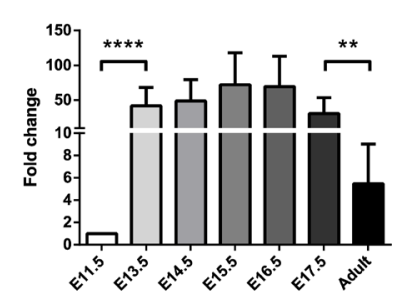

D

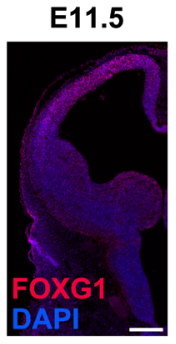

E13.5

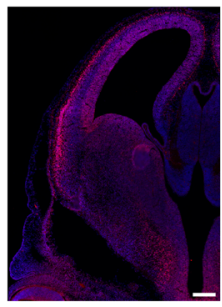

F

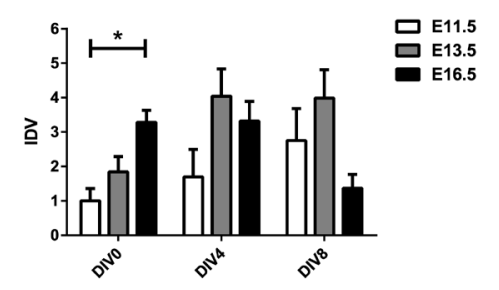

B

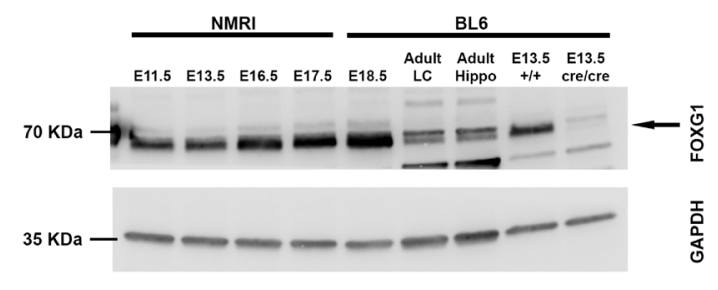

C

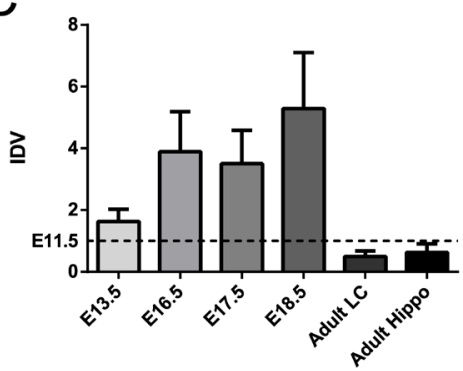

E
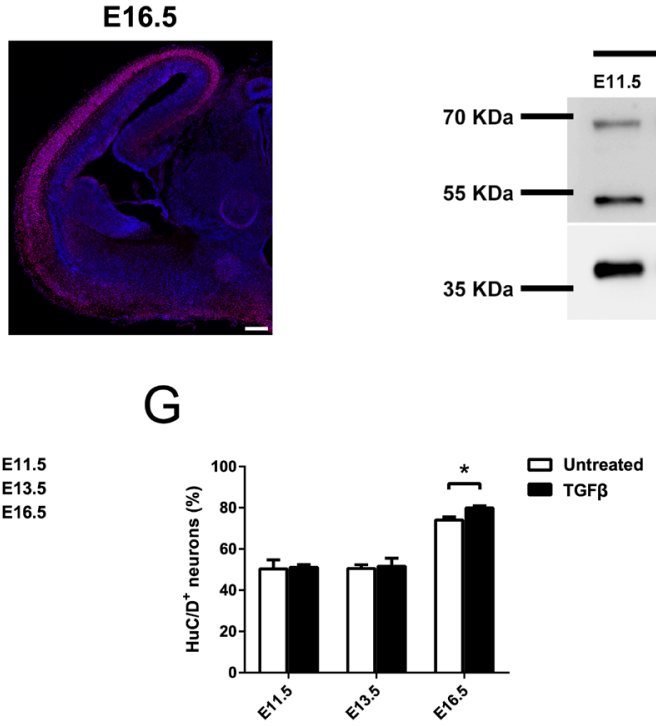

$\mathrm{H}$
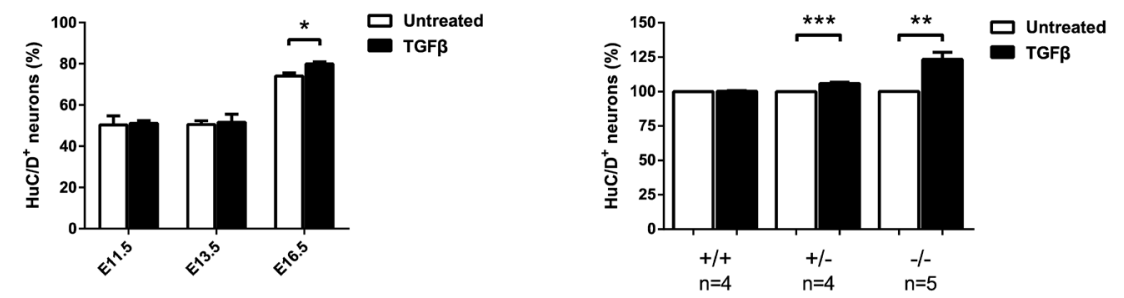

Figure 1: FOXG1 prevents TGFß-mediated neuronal differentiation at early developmental stages. A. qRTPCR analysis of Foxg1 expression from E11.5 until adulthood revealed that Foxg1 transcript levels increased significantly after E11.5 and remained stationary until they dropped at the adult stage. Values were expressed as fold change relative to E11.5 (indicated as 1 ). $* * * * p<0.0001$; ${ }^{* *} p<0.01$; One-way ANOVA - Šidák's post-test comparing consecutive developmental stages; $n=3$. B., C. Immunoblot evaluation of FOXG1 expression in murine telencephalon at different developmental time points (B) and relative densitometric analysis (C) showed a mild but not significant increase in FOXG1 levels between E11.5 (dashed line) and E13.5. The peak of expression occurred between E13.5 and E17.5 and was decreased after E17.5 in lateral cortex (LC) and in hippocampus (hippo). Brain extracts from Foxg1 ${ }^{-/}$animals were used as a negative control to correctly identify FOXG1 band (arrow). Statistical analysis: One-way ANOVA - Šidák's post-test comparing consecutive developmental stages; $n=3$. D. Immunohistochemical staining showing temporo-spatial dynamics in expression of FOXG1 in murine forebrain at different developmental stages. Scale bar: $200 \mu \mathrm{m} ; n=3$. E., F. In vitro assessment of FOXG1 protein levels on cortical cells obtained at E11.5, E13.5 and E16.5, and cultured until either DIV0, DIV4 or DIV8 (E), and their relative densitometric analysis (F). FOXG1 levels significantly increased between E11.5 and E16.5 in DIV0 cortical cells. CPCs from E11.5 and E13.5 show increased or unchanged FOXG1 expression, respectively, after 4 or 8 days in culture. FOXG1 in E16.5 cells drops at DIV8. ${ }^{*} p<0.05$; One-Way ANOVA with Tukey's post-test comparing all pairs of columns within the same DIV group; $n=3$. G. Evaluation of TGF $\beta$-induced neuronal differentiation at E11.5, E13.5 and E16.5 through HuC/D immunocytochemistry. TGF $\beta$ treatment led to an increase in the percentage of $\mathrm{HuC} / \mathrm{D}^{+}$cells as compared to untreated control only at E16.5, while no significant effects were visible at E11.5 and E13.5. ${ }^{*} p<0.05$; Student's $t$-test; $n=4$. H. Evaluation of neuronal differentiation in E13.5 wild-type, Foxg $1^{+/-}$and Foxg $1^{-/}$CPCs upon TGF $\beta$ treatment. $\mathrm{HuC} / \mathrm{D}$ immunocytochemistry showed that partial or total loss of Foxgl renders cells responsive to TGF $\beta$-induced differentiation. $* * * p<$ $0.001, * * p<0.01$; Student's $t$-test. Immunoblot results (B-E) were normalized to respective GAPDH and shown as a ratio to the E11.5 stage (set as 1 ). All data are shown as mean \pm SEM. IDV: integrated density value. 
assessed FOXG1 expression in cultured CPCs that derived from different developmental time points (E11.5, E13.5 and E16.5) and were cultured for either 0, 4 or 8 DIV. Using immunoblotting of protein extracts we showed that FOXG1 expression levels of freshly dissociated cells increased during development as observed in vivo (Figure $1 \mathrm{E}, 1 \mathrm{~F})$. However, while cultivated cells from E11.5 and
E13.5 increased or at least retained FOXG1 protein levels during the 4 and 8 day culture period, respectively, E16.5derived cells expressed decreasing levels of FOXG1 after 8 days in culture (Figure 1E, 1F). To further address whether declining FOXG1 levels promote TGF $\beta$-mediated neuronal differentiation, CPCs from E11.5, E13.5 and E16.5 were cultured for $8 \mathrm{DIV}$ in the presence of TGFB1
A

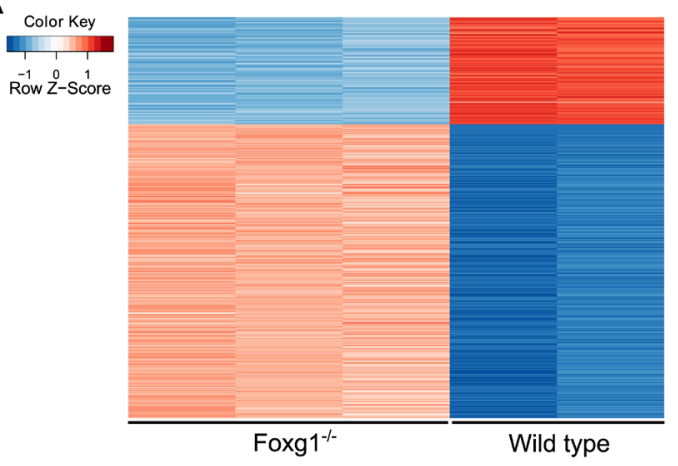

B

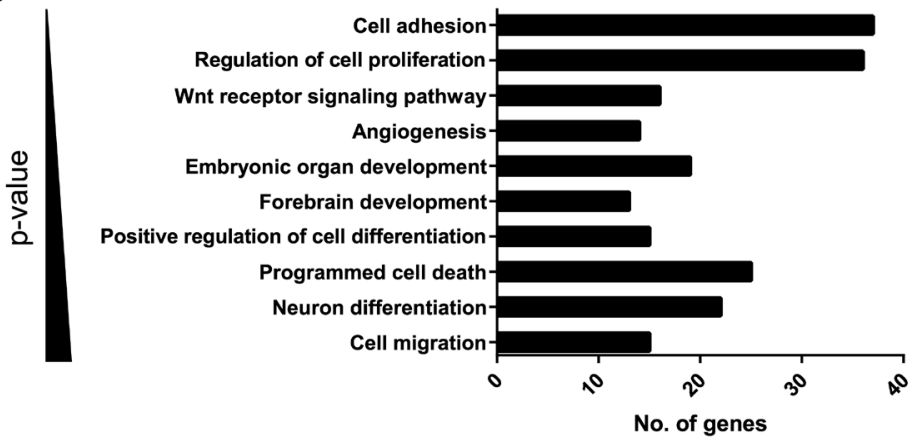

D

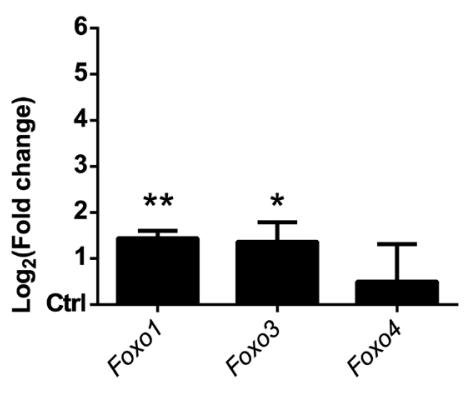

$\mathrm{F}$

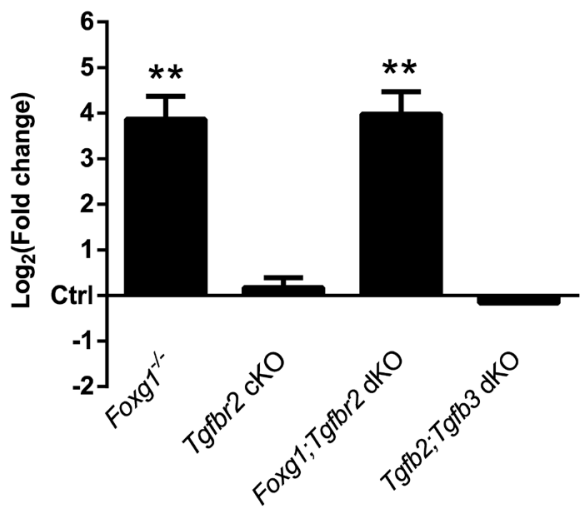

Figure 2: FOXG1 inhibits expression of Tgf $\beta$ - and $\operatorname{Ig} f$-ligands, Foxo1, Foxo3 and Cdkn1a. A. Transcriptome profiling of TGF $\beta$-treated Foxgl ${ }^{-/}(n=3)$ and wild-type $(n=2)$ CPCs identified 586 differentially regulated genes. B. Bar chart showing the main biological processes in which microarray-identified genes are involved. This analysis was performed using DAVID. C.-E. Candidate genes identified through microarray analysis were validated by qRTPCR. Transcriptional expression of $T g f b 1$ and $T g f b 2$ (C), transcription factors Foxol and Foxo3 (D) as well as Igfl and $\operatorname{Ig} f 2$ (E) was significantly increased in E13.5 Foxg 1 - forebrains as compared to wild-type controls. F. Expression of cyclin-dependent kinase inhibitor Cdknla was tested in different mutant mouse lines. Cdknla expression was decreased in Foxg1-deficient (Foxg1 ${ }^{-/}$) mice as well as in animals where both Foxg1 and Tgfbr2 were knocked out (Foxg1;Tgfbr2 dKO). Cdkn1a expression was unaffected in mice where $T g f b r 2$ was conditionally knocked out in Foxgl-expressing cells (Tgfbr2 cKO) and in double knockouts for $T g f b 2$ and $T g f b 3$ (Tgfb2; Tgfb3 dKO). Results are expressed as $\log _{2}$ (fold change) as compared to control wild-type animals (set as 0$)$. ${ }^{*} p<0.01, * p<0.05$; Student's $t$-test; $n=3$. 
from DIV2 onwards. Immunostaining and quantification of the neuronal marker $\mathrm{HuC} / \mathrm{D}$ revealed that $\mathrm{TGF} \beta$ treatment significantly increased the amount of $\mathrm{HuC} / \mathrm{D}$ positive cells at E16.5, but not at E13.5 or at E11.5 (Figure $1 G)$. Finally, we treated E13.5-derived CPCs from Foxg1deficient $\left(\right.$ Foxg $\left.1^{-/}\right)$, heterozygote $\left(\right.$Foxg $1^{+/}$) and wild-type mice with TGFB1 and quantified cells positive for the neuronal marker HuC/D. Strikingly, TGFB1 treatment increased the numbers of $\mathrm{HuC} / \mathrm{D}$-positive neurons even in CPCs of E13.5, if the expression of FOXG1 is reduced, but not in wild-type CPCs expressing normal FOXG1 levels (Figure 1H).

We concluded that expression of FOXG1 impaired TGF $\beta$-induced neuronal differentiation in a dose dependent manner at early developmental stages (E11.5 and E13.5).

\section{FOXG1 suppresses transcription of $T g f \beta$ - and $I g f-$ ligands, Foxo1 and Foxo3 transcription factors and Cdkn1a in vivo}

We next investigated the transcriptional changes in FOXG1-deficient compared to wild-type CPCs in conditions of active TGF $\beta$-signaling until DIV4. Using microarray technology, we identified 586 differentially expressed genes in FOXG1-deficient compared to wildtype cells using a cutoff of $>+1.5$ or $<-1.5 \log _{2}$ (fold change) $\left(\log _{2} \mathrm{FC}\right)$ and a p-value $\leq 0.05$. The majority of the identified genes showed increased expression (Figure 2A; Table S1). Hence, FOXG1 acts mainly as transcriptional repressor. DAVID (Database for
Annotation, Visualization and Integrated Discovery) [26, 27] analyses revealed that loss of FOXG1 affects multiple important cellular processes that are involved in brain development (Figure 2B). Loss of Foxg1 rendered E13.5derived CPCs responsive to TGF $\beta$-mediated neuronal differentiation (Figure 1H). Therefore, we analyzed whether Foxg1 deficiency antagonized the TGF $\beta$ pathway not only through association with the FOXO/ SMAD4 complex, but also through altered expression of TGF $\beta$ - and IGF-signaling pathway members. Compared to wild-type E13.5 forebrains, loss of Foxg1 increased expression of $T g f b 1$ and $T g f b 2$ (Figure 2C), Foxo1 and Foxo3 (Figure 2D), and Igf1, Igf2, and Igfbp2 (Figure $2 \mathrm{E}$ ). We concluded that FOXG1 is not only antagonizing TGF $\beta$ - and FOXO-functions on the protein level but also on the transcriptional level.

To further assess the antagonizing function of FOXG1 on SMAD- and FOXO-driven transcription of $C d k n l a$, we analyzed $C d k n l a$ transcription in different mouse models in E13.5 forebrains. To address the impact of FOXG1 on Cdknla transcription, we used Foxgl knockout mice (Foxg1 $1^{-/}$). The TGFBR2 is specifically activated by the TGF $\beta$-ligands, whereas the TGFBR1 is also activated by other ligands of the TGF $\beta$-superfamily. We therefore used TGFBR2-deficient mice to assess the involvement of TGF $\beta$-signaling in Cdknla transcription. TGFBR2-deficiency was achieved through conditional knockout of Tgfbr2 using a cre-knockin into the Foxg1gene (Tgfbr2 cKO). Accordingly, these mice express reduced levels of FOXG1 and have impaired TGFBR2signaling in the same cells. We also generated FOXG1 and TGFBR2 double-deficient mice (Foxg1;Tgfbr2 dKO).
A

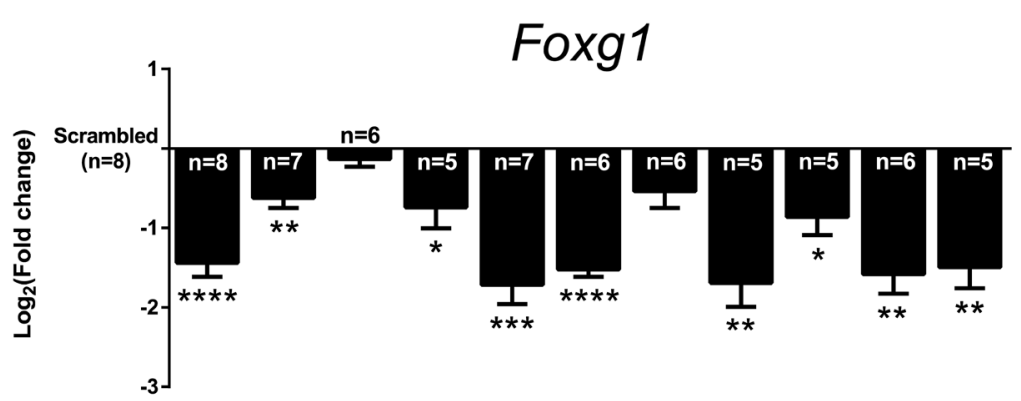

B

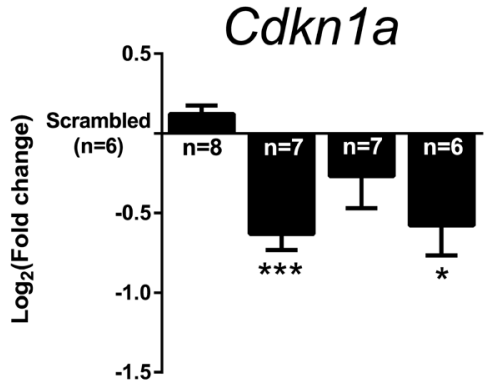

$$
\begin{aligned}
& \text { Foxg1 shRNA } \\
& \text { Foxo1 shRNA } \\
& \text { Foxo3 shRNA } \\
& \text { Smad4 shRNA }
\end{aligned}
$$

Figure 3: Knockdowns of Foxg1, Foxo1 and Smad4 affect expression of each other and of Cdkn1a. A., B. E13.5 murine CPCs were infected with shRNA constructs targeting specific genes or scrambled shRNA construct (control). Expression levels of Foxg1 and Cdknla were assessed by qRTPCR. A. Foxgl transcript levels were significantly decreased when shRNA constructs targeted Foxgl, Foxo1, Smad4 or their combinations. B. Cdknla expression was significantly decreased upon knockdown of Foxol or Smad4, but not upon Foxo3 or Foxg1 knockdown. Results are shown as mean of $\log _{2}($ fold change $) \pm$ SEM in specific shRNA construct condition $v s$. scrambled control (set as 0 ). ${ }^{* * * *} p<0.0001,{ }^{* * *} p<0.001,{ }^{* *} p<0.01,{ }^{*} p<0.05$; One-sample $t$-test; replicate numbers indicated in graphics. 
Whereas TGFB1 is mainly expressed in the meninges of the forebrain, TGFB2 and TGFB3 ligands are mainly expressed by neural cells [28]. We therefore assessed Cdkn1a in TGFB2 and 3 double deficient forebrains (Tgfb2;Tgfb3 dKO), which served as additional model system for impaired TGF $\beta$-signaling. As displayed in Figure 2F, only the complete loss of Foxgl increased expression of Cdknla in vivo. At this developmental stage, loss of TGFBR2 in FOXG1-expressing cells or constitutive lack of TGFB2 and 3 ligands did not seem to be relevant for Cdknla transcription in vivo.

\section{FOXG1, FOXO1 and SMAD4 form a regulative network to drive their own and $C d k n 1 a$ expression}

FOXG1, FOXO1, FOXO3 and SMAD4 form a network implicated in controlling $C d k n l a$ expression. In addition, FOXG1 interfered with transcription of Foxol and Foxo3 in vivo (Figure 2D). We therefore evaluated transcriptional changes of this network on its own members and on Cdknla in vitro using shRNA-mediated knockdown of single components and their combinations. Knockdown of Foxgl led to a moderate decrease of its own expression by approximately $63 \%\left(\log _{2} \mathrm{FC}=-1.44\right.$; Figure 3A). This is little less than the Foxgl expression that we observed in heterozygote animals (Figure S1). Foxg1 transcription was also decreased after knockdown of Foxol and of Smad4, either alone or in combination.
In contrast, the expression of Foxo1, Foxo3 and Smad4 was exclusively affected when shRNAs against their own mRNAs were used (Figure S2). Thus, although loss of Foxg1 in vivo indicated that FOXG1 is implicated in transcriptional control of Foxol and Foxo3, the level of suppression of FOXG1 using the shRNA (63\%) was not sufficient to induce Foxol and Foxo 3 transcription in vitro.

We next assessed the expression of Cdknla in this in vitro setup. We observed that shRNA-mediated Foxgl knockdown did not cause an increase in Cdknla expression (Figure 3B). We concluded that even low expression of Foxgl efficiently blocked the transcription of this cell cycle inhibitor. This conclusion is supported by the in vivo data, which showed that loss of one Foxg1 allele is not sufficient to increase Cdknla levels in vivo in Tgfbr2 cKO, whereas loss of both Foxg1 alleles strongly increases Cdknla levels (Figure 2F). Knockdown of Foxol and Smad4 suppressed Cdknla levels. In contrast, knockdown of Foxo3 did not result in significant changes of Cdknla transcription (Figure 3B).

We concluded that FOXG1 suppresses the expression of Foxo1, Foxo3 and Cdknla. FOXO1 in turn increases not only the expression of Cdknla but also that of its repressor Foxg1. Smad4 also increases Cdknla and Foxg1 transcription in vitro. Thus, aside from forming protein complexes with FOXO and SMAD4, FOXG1 interferes with the transcription of Tgf $\beta$ and Foxo genes that oppose mitosis of cortical progenitors.
A

E11.5

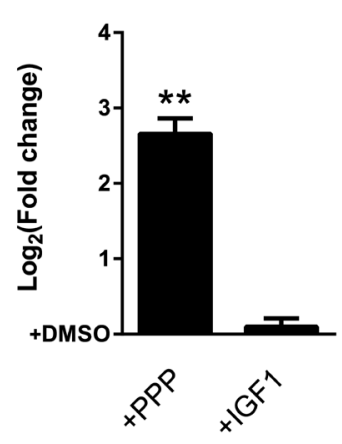

B

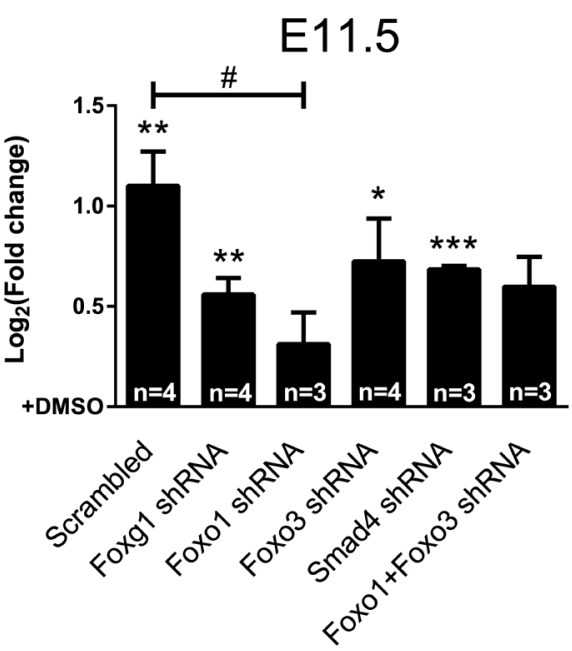

C

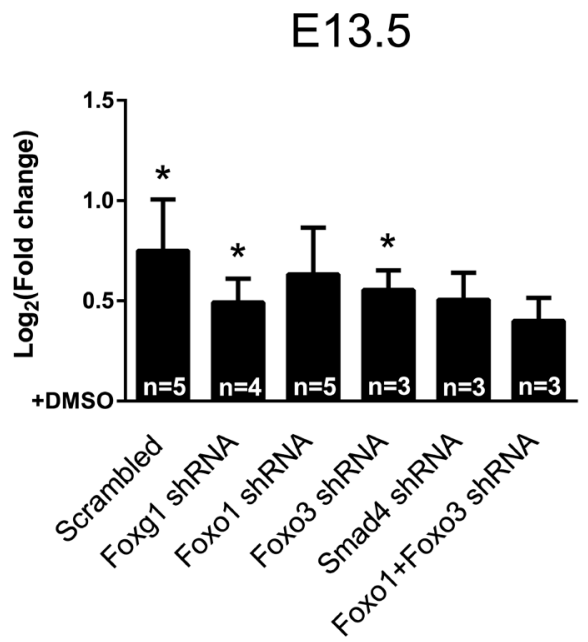

Figure 4: IGF1-pathway affects $\boldsymbol{C d k n 1 a}$ expression through FOXO1. A. Cdknla expression in E11.5 CPCswas significantly increased after blocking intracellular IGF1-signaling with PPP. Treatment with IGF1 did not affect Cdkn1a expression. B., C. Cdknla expression was assessed in E11.5 (B) and E13.5 (C) CPCs after knocking down the expression of Foxg1, Foxo1, Foxo3, Smad4 or Foxo1+Foxo3 while blocking IGF1-signaling by PPP treatment. (B) Expression of Cdknla increased in E11.5 CPCs upon treatment with PPP except when Foxol expression was knocked down. (C) Cdknla expression in E13.5 CPCs was not significantly raised upon PPP treatment when either Foxol or Smad4 expression was knocked down. Results are shown as mean of $\log _{2}$ (fold change) \pm SEM of each PPPtreated condition $v s$. relative DMSO-treated control ( control). $\# \mathrm{p}<0.05$; One-way ANOVA - Dunnet's post-test (vs. Scrambled control). Replicate number in A: $n=4$. 


\section{IGF-signaling drives $C d k n 1 a$ expression through FOXO1}

IGF-signaling activates PI3K, which subsequently leads to phosphorylation of FOXO proteins and exclusion from the nucleus $[12,29,30]$. As our data showed that deficiency of FOXG1 increased expression of IGFpathway members (Figure 2E), we analyzed the effects of IGF-signaling on Cdknla expression in the context of the FOXG1/FOXO1/FOXO3/SMAD4 transcriptional network. We have recently shown that IGF-signaling is highly active in CPCs that derive from early developmental time points (E11.5 and E13.5), whereas it does not have large impact at later stages (E16.5) [2]. Hence, we hypothesized that IGF-signaling is involved in Cdknla expression in E11.5 and E13.5 CPCs. We isolated CPCs from E11.5 mouse brains, treated them with Picropodophyllin (PPP), IGF1 or DMSO. Using qRTPCR, we observed that $C d k n 1 a$ expression increased in E11.5derived CPCs when IGF1-signaling was blocked with PPP (Figure 4A). This result is in accordance with IGFdependent activation of AKT-mediated phosphorylation of FOXO proteins that translocates FOXOs into the cytoplasm and interferes with their activating effects on transcription. It also reflects that IGF-signaling mediates proliferation of CPCs. Treatment of E11.5-derived CPCs with IGF1 did not result in transcriptional repression of Cdkn1a (Figure 4A). This is probably because of high expression levels of IGF1 at these early developmental stages [2] that might be sufficient to fully activate the pathway.

Next, we analyzed whether IGF1-signaling interfered with Cdknla transcription by impinging on FOXO1 and/or FOXO3. The shRNA knockdown experiments (Figure 3B) suggested that FOXO1 activates Cdknla expression, which might be prevented by IGFmediated FOXO1 phosphorylation (Figure 4A). Hence, interference with FOXO1 expression should prevent transcriptional activation of Cdknla after inhibition of IGF1-signaling. In contrast, reduced FOXO3 expression might not alter Cdkn1a transcript levels when IGF1signaling is inhibited. To show this, we infected E11.5derived CPCs with lentiviral shRNAs against specific members of the FOXG1/FOXO1/FOXO3/SMAD4 transcriptional network and subsequently blocked IGF1signaling with PPP. Blocked IGF1-signaling induced Cdkn1a transcription in nearly all conditions compared to respective DMSO controls, except in conditions with a knockdown of Foxol (Figure 4B). In addition, compared to the scrambled control, knockdown of Foxol was the only condition, which resulted in significantly decreased expression of Cdknla. This finding further corroborated that FOXO1 but not FOXO3 is important to activate Cdkn 1a transcription. Next, we assessed whether these transcriptional changes were also observed in E13.5 CPCs. Although induction of Cdknla transcription was generally less pronounced compared to E11.5-derived cells, IGF-signaling mainly affected FOXO1-mediated transcriptional activation of $C d k n 1 a$. In accordance with our observations in E11.5-derived CPCs, interference with Foxol expression in E13.5-derived cells was one condition in which $C d k n 1 a$ was not significantly induced after PPP treatment (Figure 4C). Interference with Smad4 reduced Cdknla expression after PPP treatment as well, indicating a growing influence of the TGF $\beta$ pathway on $C d k n 1 a$ transcription during development. Again, interference with Foxo3 expression did not impair Cdknla expression after PPP treatment. We did not observe changes in localization of FOXO3 upon PPP or IGF1 treatment (Figure S3). This further suggests that FOXO3 might not be relevant in IGF1-mediated control of Cdknla expression. Hence, we concluded that expression of Cdkn la is activated by FOXO1, and not by FOXO3 in E11.5 and E13.5 cells.

\section{TGFß-signaling is not sufficient to induce differentiation of Calb2-expressing Cajal-Retzius cells}

The FOXG1/FOXO1/FOXO3/SMAD4-network does not only control cell cycle exit, but also regulates differentiation of CR cells. TRP73-expressing CR cells derive from the cortical hem, which does not express FOXG1. Another CR-producing region is the pallialsubpallial boundary (PSB), in which progenitors express FOXG1 and generate CALB2-positive CR neurons. In the cortical hem, TGF $\beta$-signaling is involved in the generation of TRP73-positive CR cells, because FOXG1 is not present in this region and is not antagonizing CR cell generation [19]. We explored whether TGF $\beta$ increased CR cell differentiation in the FOXG1-expressing PSB in conditions of reduced FOXG1 levels. We assessed expression of Reln, Trp 73 and Calb2 in Foxg1 $1^{-/}$, Tgfbr2 cKO and Foxg1;Tgfbr2 dKO forebrains. Foxg1-deficient mice expressed increased levels of Reln, which indicates general CR cell overproduction. The Tgfbr $2 \mathrm{cKO}$ mice did not show increased Reln expression. Trp 73 was strongly increased in both Foxg1-deficient mouse models, but only slightly in Tgfbr2 cKO (Figure 5A). Expression of Calb2 increased in all three mouse models as compared to control animals. We concluded that FOXG1 expression is not antagonizing TGF $\beta$ activated differentiation of Calb2expressing CR from the PSB. Otherwise, expression of Calb2 would be reduced in forebrains that are deficient for both, TGF $\beta$-signaling and FOXG1. This result was also confirmed by immunohistochemistry stainings of CALB2 in the different mouse lines (Figure 5B). 


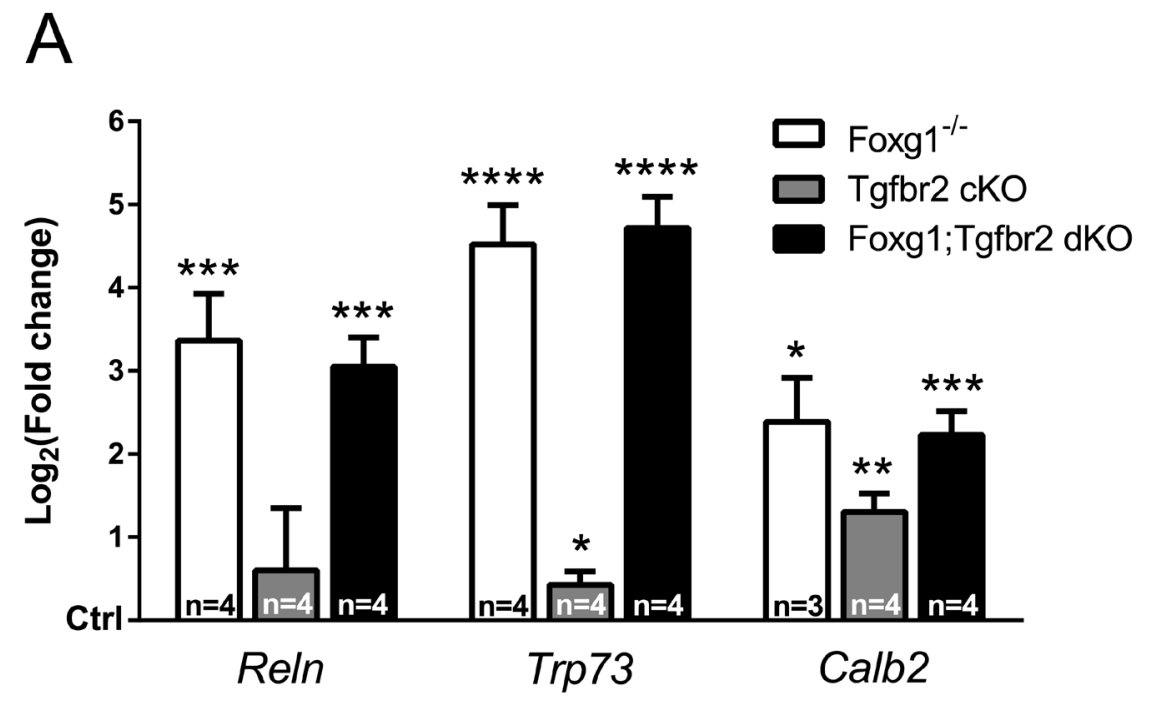

B

\section{Control}

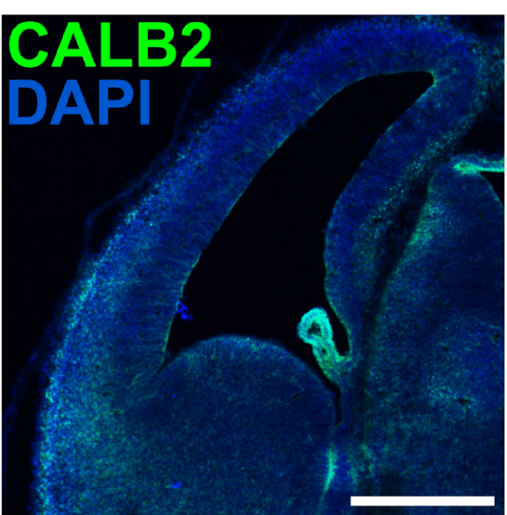

Foxg1 $1^{-/}$

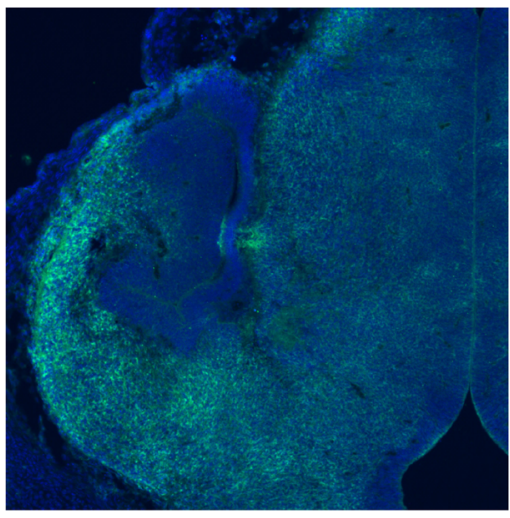

Tgfbr2 cKO
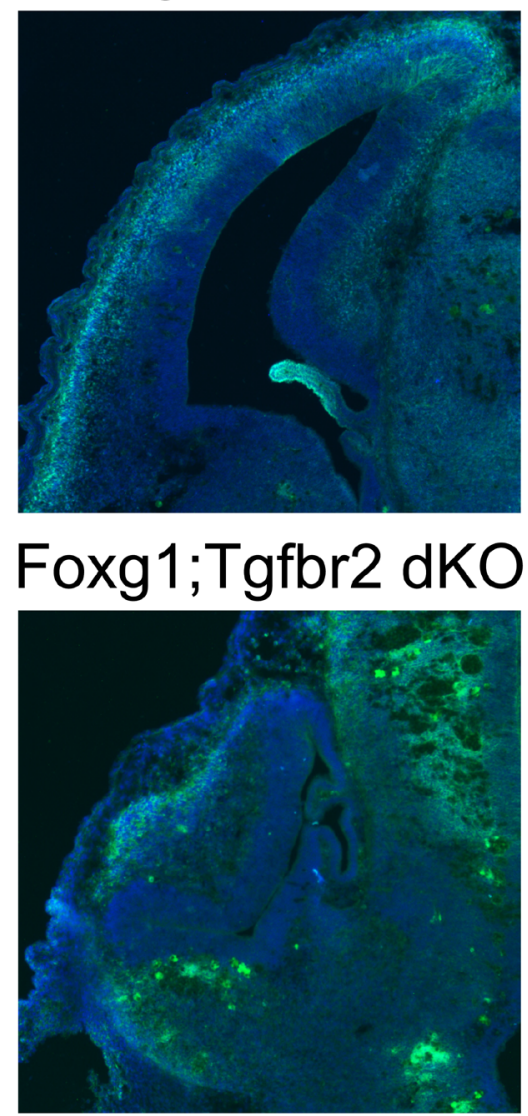

Figure 5: Evaluation of FOXG1/TGF $\beta$-pathway crosstalk in specification of Cajal-Retzius (CR) cells. A. qRTPCR-based analysis of the expression of CR cell markers in E13.5 Foxg1 ${ }^{-/}$, Tgfbr2 $\mathrm{cKO}$ and Foxg1;Tgfbr2 dKO mice. Transcriptional expression of Reln, Trp 73 and Calb2 was significantly increased in all models lacking Foxg1 expression. Reln expression was not affected by loss of Tgfbr2. Trp 73 and Calb2 transcripts were mildly increased in Tgfbr2 cKOs. B. Immunohistochemical analysis of brain sections from E13.5 Foxg1 ${ }^{--}$, Tgfbr2 cKO, Foxg1;Tgfbr2 dKO as well as corresponding controls, showed that CALB2 expression is increased upon loss of Foxg1 expression. Consistent with the qRTPCR results, the amount of CALB2-positive cells was not decreased in Tgfbr2 cKO mice. qRTPCR results are shown as mean of $\log _{2}$ (fold change) \pm SEM of each condition $v$ s. relative control (set as 0 ). $* * * * p<0.0001, * * * p<$ $0.001,{ }^{* *} p<0.01,{ }^{*} p<0.05$; Student's $t$-test; $\mathrm{n} \geq 3$. Scale bar: $250 \mu \mathrm{m}$. 


\section{Overexpression of Cdkn1a or interference with FOXO1 or FOXO3 does not alter neuronal differentiation}

We further investigated whether overexpression of Cdknla alone would be sufficient to increase neuronal differentiation. We infected E13.5-derived CPCs with a lentiviral CDKN1A overexpression construct and stained for the neuronal marker HuC/D. Quantification of HuC/Dpositive CDKN1A-overexpressing cells compared to cells carrying the empty vector did not reveal increased neuronal differentiation. This was independent of TGF $\beta$ stimulation

A
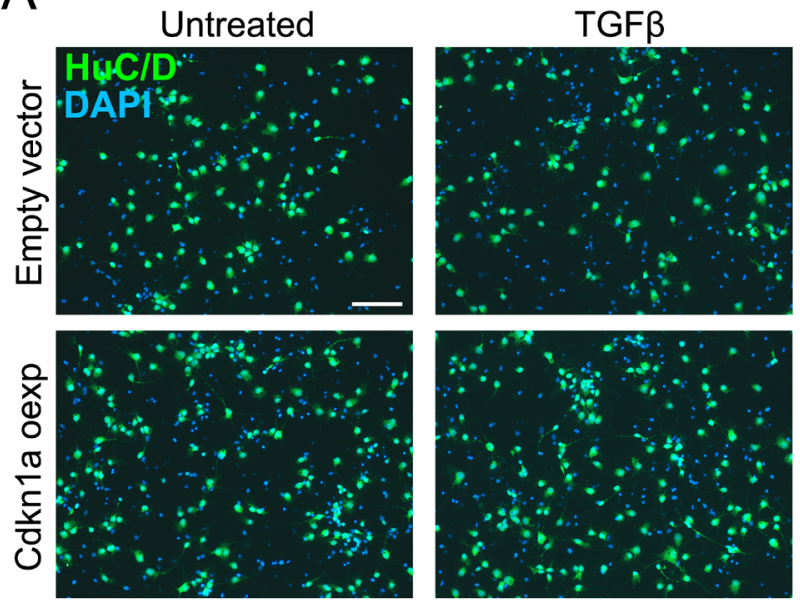

C

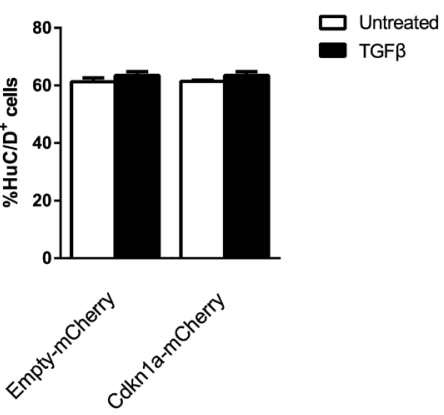

(Figure 6A, 6C). To assess whether FOXO1 and FOXO3 increased neuronal differentiation, we interfered with their expression using shRNAs in E13.5-derived CPCs and determined the number of $\mathrm{HuC} / \mathrm{D}$-expressing neurons. We did not observe a striking influence of either FOXO protein on the generation of neurons. Only mild effects on neuronal differentiation were uncovered that opposed each other (Figure 6B, 6D). Whereas interference with FOXO1 led to a small but significant increase in the number of neurons in untreated conditions, interference with $\mathrm{FOXO} 3$ led to a slight decrease in $\mathrm{HuC} / \mathrm{D}$-positive neurons after stimulation with TGF $\beta$, indicating a mild differentiating effect of FOXO3. We concluded that FOXO1 and FOXO3

B
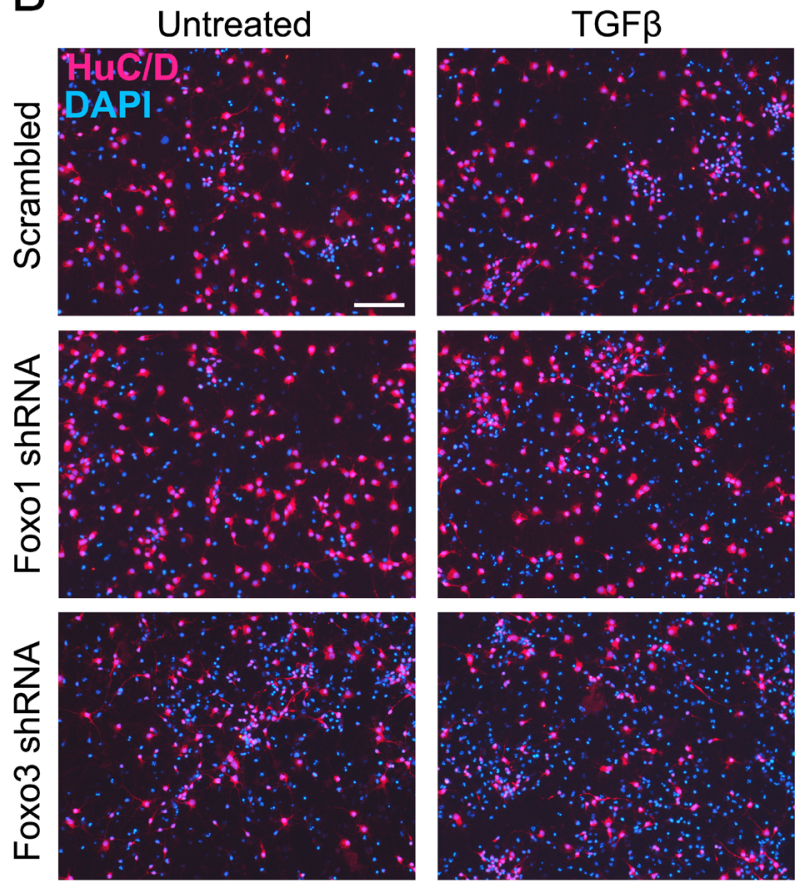

$\mathrm{D}$

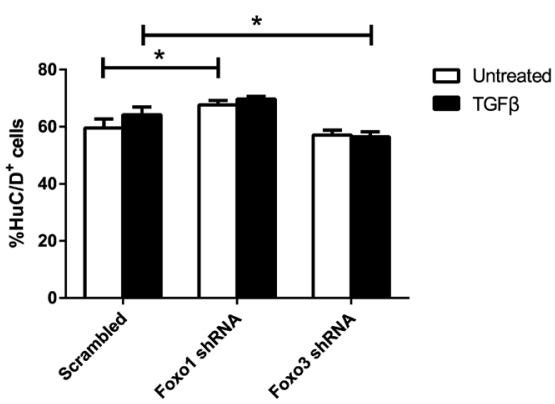

Figure 6: Neuronal differentiation at E13.5 is unaffected by Cdkn1a overexpression or loss of Foxo1 and Foxo3. A., C. Immunocytochemical analysis of $\mathrm{HuC/D}$ expression (A) showed that overexpression of $C d k n 1 a$ is not sufficient to induce neuronal differentiation in E13.5 CPCs. The percentage of $\mathrm{HuC} / \mathrm{D}^{+}$cells after $C d k n 1 a$ overexpression with or without TGFB1 stimulation (6 days) did not change significantly compared to E13.5 CPCs infected with empty vector (C). B., D. Immunocytochemical staining for HuC/D performed on E13.5 CPCs infected with shRNA constructs targeting Foxol or Foxo3, either treated with TGFB1 for 6 DIV or left untreated. Knockdown of Foxol led to a mild but significant increase in untreated $\mathrm{HuC} / \mathrm{D}^{+}$cells, while knockdown of Foxo3 expression decreased the amount of TGF $\beta$-treated HuC/ $/ \mathrm{D}^{+}$cells. ${ }^{*} p<0.05$; One-way ANOVA - Šidák's post-test for comparison of specific pairs; $n=3$. Scale bar: $100 \mu \mathrm{m}$. 
might have opposing effects on neuronal differentiation and that FOXO1 and FOXO3 have non-redundant functions, which were also revealed by differences in the transcriptional control of Cdknla and Foxgl. These data also indicated that FOXO1 does not activate downstream genes that increase neuronal differentiation at E13.5.

\section{FOXG1 activates Kcnh3 transcription}

We further analyzed our microarray data to assess which genes other than $C d k n 1 a$ were regulated by FOXG1 in a context of active TGF $\beta$-signaling. Comparison between expression profiles of TGF $\beta$-treated Foxg $1^{-/-}$and wild-type E13.5 CPCs showed differential expression of many genes involved in a great variety of biological processes (Figure 2A, 2B; Table S1). Such processes spanned from neuronal differentiation to apoptosis, from cell migration and adhesion to angiogenesis. To identify genes that are regulated through a FOXG1/ TGF $\beta$ crosstalk, we first analyzed the whole mouse genome by searching for gene promoters that contained both FOX (GTAAACAA) and SMAD4 (AGAC) DNAbinding sites using SiteSearch software [31]. For this genome-wide screen, we analyzed DNA regions $15 \mathrm{~Kb}$
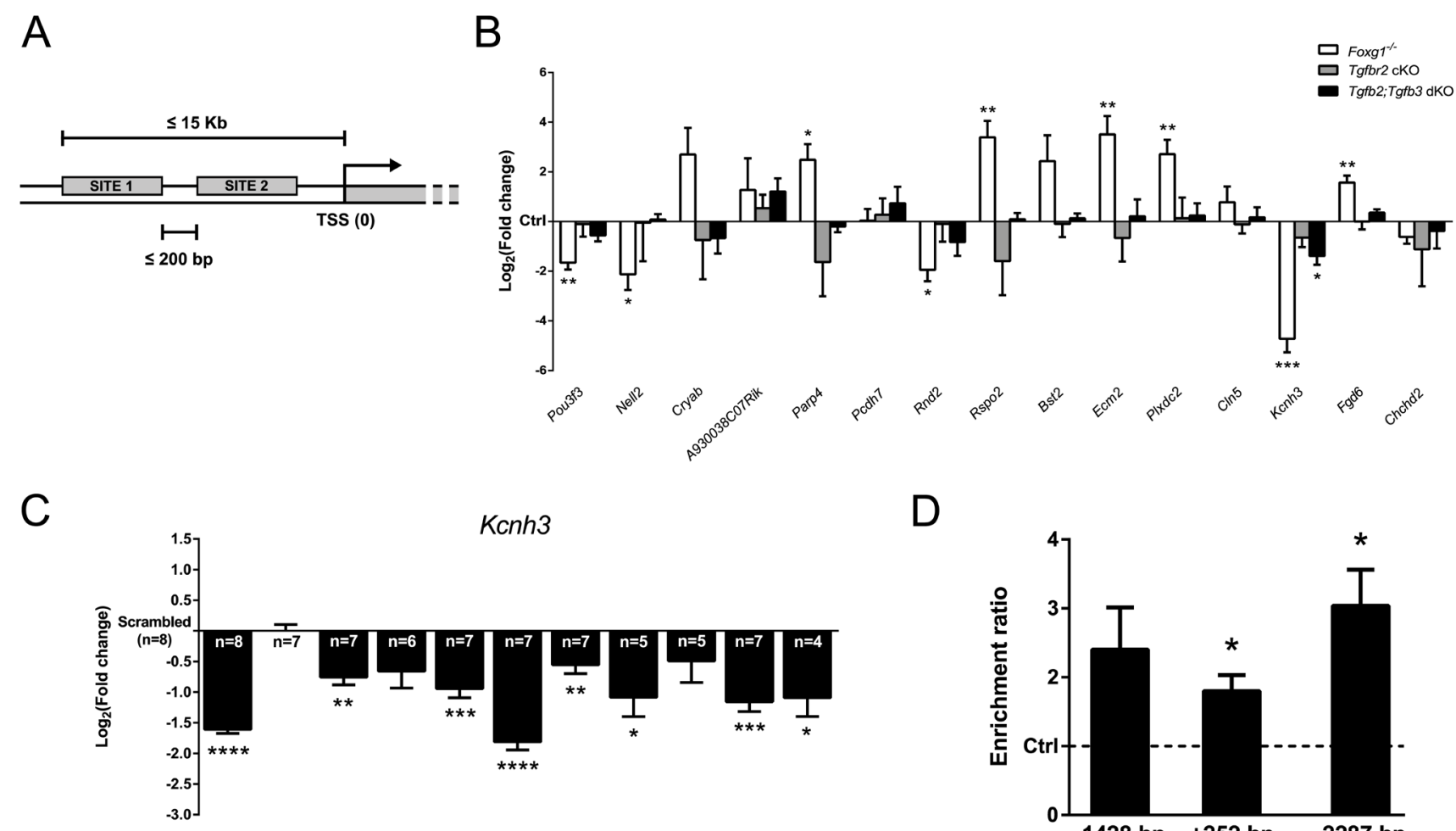

$$
\begin{aligned}
& \text { Foxg1 shRNA } \\
& \text { Foxo1 shRNA } \\
& \text { Foxo3 shRNA } \\
& \text { Smad4 shRNA } \\
& \begin{array}{llll}
+ & - & - & - \\
- & + & - & - \\
- & - & + & - \\
- & - & - & +
\end{array} \\
& \begin{array}{cc}
+ & + \\
+ & - \\
- & + \\
- & -
\end{array} \\
& \begin{array}{llll}
+ & - & + & + \\
- & + & + & + \\
- & - & + & - \\
+ & + & - & +
\end{array}
\end{aligned}
$$

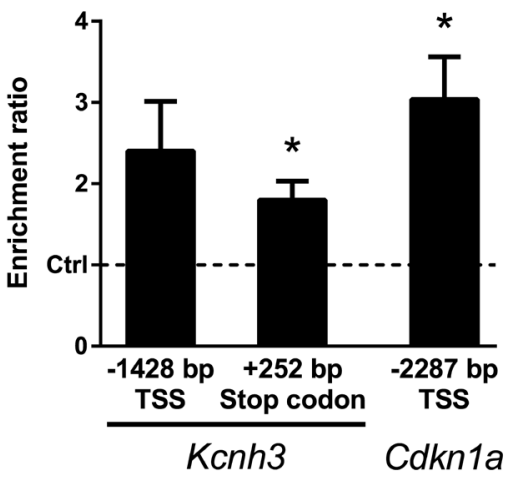

Figure 7: Identification of novel candidate genes regulated through FOXG1/SMAD crosstalk. A. Whole mouse genome was screened for genes possessing both Forkhead box- (GTAAACAA) and SMAD4-specific (AGAC) consensus DNA-binding sites in a range of $15 \mathrm{~Kb}$ before the TSS and placed not farther than $200 \mathrm{bp}$ from each other. Selected candidate genes fulfilled these criteria and were regulated in our microarray analysis. B. Transcriptional expression of candidate genes was assessed by qRTPCR using E13.5 telencephalic hemispheres from Foxg1 ${ }^{-/}, T g f b r 2 \mathrm{cKO}$ and $T g f b 2 ; T g f b 3 \mathrm{dKO}$ mice. Results are expressed $\log _{2}$ (fold change) \pm SEM of target gene expression in mutants as compared to respective controls (Ctrl, set as 0 ). Kcnh3 was found to be regulated in both Foxg $1^{-/}$and Tgfb2; Tgfb3 $\mathrm{dKO}$ mice and was thus selected for further analyses. ${ }^{* *} p<0.001,{ }^{* *} p<0.01,{ }^{*} p<0.05$; Student's $t$-test; $n=3$. C. Kcnh3 expression in wild-type E13.5 CPCs infected with shRNA constructs targeting Foxg1, Foxo genes and Smad4 decreased when either Foxg1 or Foxo3 were knocked down. Results are shown as mean of $\log _{2}$ (fold change) \pm SEM in specific shRNA construct condition $v s$. scrambled control (set as 0 ). ${ }^{* * * *} p<0.0001,{ }^{* * *} p<0.001,{ }^{* *} p<0.01,{ }^{*} p<0.05$; One-sample $t$-test; replicate numbers indicated on graphics. D. Potential binding of FOXG1 at specific sites upstream of Kcnh3 as well as at the 3'-UTR was investigated using ChIP. FOXG1 was enriched in 3'UTR region (252-287 bp downstream from the termination codon; reference NM 010601.3). Significant FOXG1 binding also occurs on the Cdknla locus (2287-2252 bp upstream of TSS; reference NM_007669.4) at the FOX-binding site described by Seoane et al. [7]. Results are shown as a ratio between FOXG1 enrichment at a specific site and its enrichment in a region devoid of FOX binding sites, which was used as a negative control (set as 1 and shown by a dashed line). ${ }^{*} p<0.05$; One sample $t$-test; $n=5$. 
upstream of all transcription start sites (TSS), and added the constraint that both FOX and SMAD4 binding sites must be located within $200 \mathrm{bp}$ of each other (Figure 7A). The resulting gene list was compared with the microarray results and shortlisted candidates were validated through qRTPCR analysis. We used RNA from cerebral cortex of E13.5 Foxg1 ${ }^{-/}$, Tgfbr2 cKO and Tgfb2;Tgfb3 dKO mice, respectively. Many candidates were regulated in Foxg $1^{-/-}$mice, confirming the microarray results (Figure 7B; Table S1). Out of all short-listed genes only Kcnh3, a gene encoding for a member of the ether-à-go-go family of voltage gated $\mathrm{K}^{+}$channels [32], was transcriptionally decreased in both Foxg1 $1^{-/}$and Tgfb2;Tgfb3 dKO. However, Tgfbr2 cKO mice did not reveal significant changes in the expression of Kcnh3. Thus, although FOX and SMAD4 DNA-binding sites were identified upstream of the Kcnh3 TSS, the influence of TGF $\beta$-signaling on Kcnh3 expression was less compared to FOXG1. In contrast to its repressive function in Cdknla transcription, FOXG1 activated Kcnh3 transcription. We next assessed whether further members of the FOXG1/FOXO1/FOXO3/ SMAD4 transcriptional network were also involved in Kcnh3 expression. We used lentiviral shRNAs to interfere with the expression of individual members and combinations of them in vitro. Corroborating our in vivo results, $K c n h 3$ was strongly decreased in all conditions of FOXG1-deficiency (Figure 7C). Whereas FOXO1 was not involved in transcriptional regulation of $K c n h 3$, loss of FOXO3 impaired Kcnh3 expression. Interference with SMAD4 did not significantly change Kcnh3 expression,
A
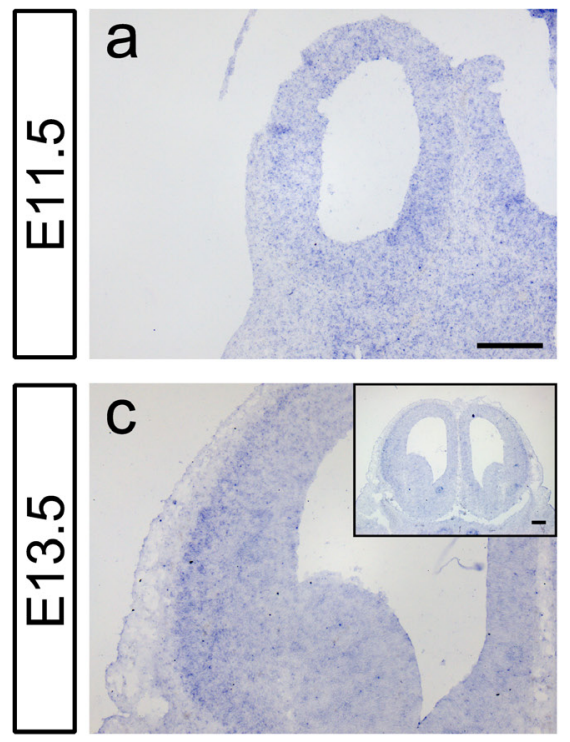

C

山

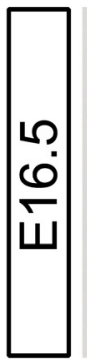

b
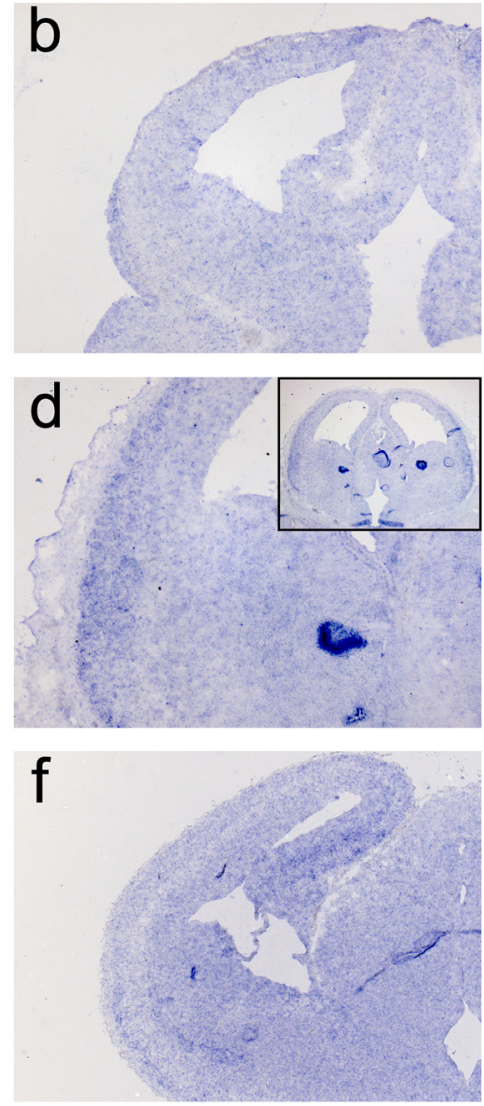

B
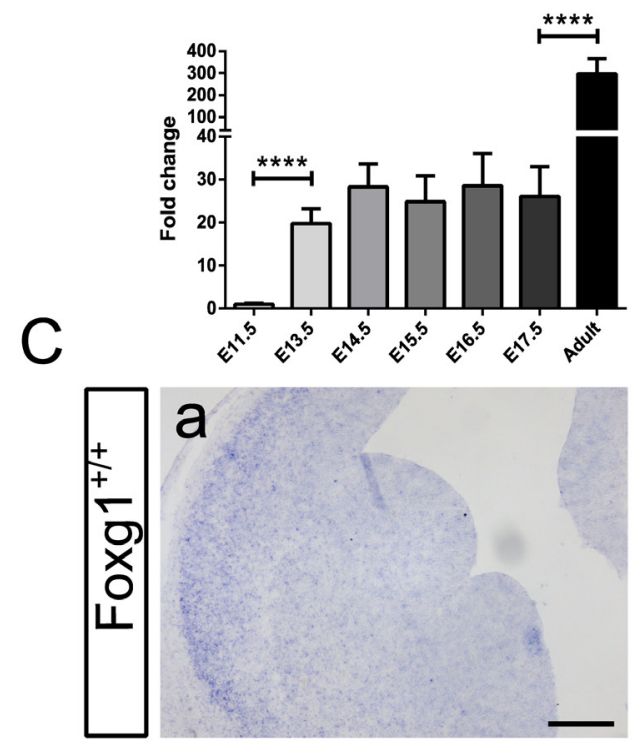

a

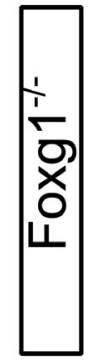

b

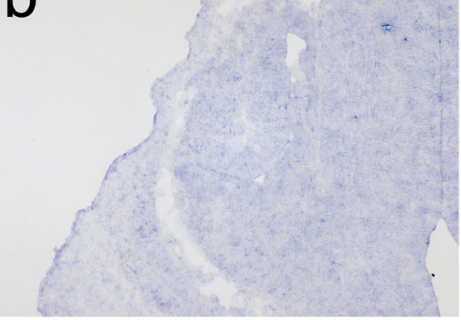

Figure 8: Characterization of spatial and temporal expression of $\mathbf{K c n h} 3$ in the developing murine forebrain. A. Kcnh3expressing regions were identified by in situ hybridization on sections from E11.5 (Aa-b), E13.5 (Ac-d) and E16.5 (Ae-f) murine forebrains. While no specific staining could be detected at E11.5 (Aa-b), at E13.5 weak to mild expression was detectable in the regions corresponding to the rostral lateral pallium (Ac) to the developing lateral entorhinal cortex (Ad). At E16.5, Kcnh3 expression took place in the same regions as at E13.5 (Ae-f), as well as in the developing hippocampus (Af). B. qRTPCR analysis showed transcriptional levels of Kcnh3 in the forebrain at different developmental stages (E11.5, E13.5, E14.5, E15.5, E16.5, E17.5 and adult). Kcnh3 expression increased between E11.5 and E13.5, remained stationary until E17.5, and increased at the adult stage. Values are expressed as relative fold change in comparison to E11.5 (indicated as 1). ${ }^{* * * *} p<0.0001$; One-way ANOVA - Šidák's post-test comparing consecutive developmental stages; $n=3$. C. Kcnh3 expression in forebrains of Foxg $1^{-/}(\mathrm{Cb})$ as compared to wild-type $(\mathrm{Ca})$ animals. Kcnh3 was undetectable in Foxg $1^{-/}$. Experimental replicates: $n=3$ for all in situ hybridization experiments, except for Foxg1 $1^{-/}(n=2)$. Scale bar: $200 \mu \mathrm{m}$. 
supporting our in vivo results that indicated no significant contribution of TGFBR2-mediated signaling to Kcnh3 expression. We concluded that Kcnh3 expression is increased by FOXG1 and FOXO3, but is independent of FOXO1 and TGF $\beta$-signaling.

For a more detailed analysis of the Kcnh3 promoter, we used the ConTra v2 software [33], which allows analyses of individual genes as compared to the genomewide approach of SiteSearch. ConTra v2 matrix-based sequence analysis of conserved motifs was performed within the promoter region and in the 3'-UTR of Kcnh3. The promoter analysis was restricted to $1500 \mathrm{bp}$ upstream of the TSS. Using this method, we identified the closely located and conserved FOX- and SMAD4-binding sites 1428-1397 bp upstream of the Kcnh3 TSS (reference NM_010601.3). As our expression data did not reveal TGF $\beta$-dependent transcription of $K c n h 3$, we also analyzed the Kcnh3 gene locus for isolated FOX-binding sites independent of SMAD4-target sequences. We identified an additional conserved FOX target sequence in the 3'UTR region 252-287 bp downstream of the termination codon of Kcnh3. The study by Seoane et al. [7] did not report whether FOXG1 is localized at the chromatin of the Cdknla gene. Thus, we aimed to reveal whether FOXG1 is present at the putative binding sites in the Cdknla and Kcnh3 genes. We employed chromatin immunoprecipitation (ChIP) of FOXG1 on chromatin isolated from dorsal telencephalic CPCs derived from E13.5 wild-type mice. Enrichment at the specific sites was compared to an intergenic region devoid of putative FOX protein DNA-binding sequences (Figure 7D). We revealed strong and significant enrichment of FOXG1 at the forkhead binding site in the Cdknla gene that is located near the SMAD4-binding sites 2287-2251 bp upstream of the TSS (reference NM_007669.4). Hence, Cdknla repression by FOXG1 probably includes its presence on the chromatin. We also detected significant enrichment of FOXG1 at the Kcnh3 3'-UTR site, whereas the enrichment at the upstream candidate sequence showed a trend but was not significant (Figure 7D). We therefore concluded that FOXG1 exerts transcriptional activation or repression either directly or indirectly associated with the chromatin.

\section{Kcnh3 is mainly expressed in lateral pallium, lateral entorhinal cortex and hippocampus during development}

As the expression pattern of Kcnh3 during embryonic development has not yet been described, we performed in situ hybridization (ISH) for Kcnh3 on wildtype murine brain sections at different developmental stages (E11.5, E13.5 and E16.5).

No specific staining was detected at E11.5 (Figure 8Aa-b). At E13.5, a weak to mild expression occurred from the region corresponding to the rostral lateral pallium (Figure 8Ac) to the developing lateral entorhinal cortex (Figure 8Ad). At E16.5, the detection of the Kcnh3 transcript extended to the developing hippocampus (Figure 8Ae-f). qRTPCR analysis of Kcnh3 transcript levels in cerebral hemispheres at different developmental stages were consistent with the results obtained by ISH. The expression increased from nearly undetectable levels (E11.5) to moderate levels (E13.5 to E17.5), finally reaching a high level of expression at the adult stage (Figure 8B).

ISH performed on sections from Foxg $1^{-/}$animals (Figure $8 \mathrm{Cb}$ ) did not show any noticeable Kcnh3 signal when compared to sections from wild-type controls (Figure 8Ca). These observations confirmed the qRTPCR results of Kcnh3 expression in Foxg $1^{-/-}$animals (Figure 7B), and in CPCs after shRNA-mediated Foxg1 knockdown (Figure 7C), in which Kcnh3 levels were also decreased compared to controls. We concluded that $K c n h 3$ is a direct target of FOXG1 and that its expression is mainly confined to mature neurons, the generation of which is impaired in Foxgl-deficient mice.

\section{DISCUSSION}

Seoane et al. [7] established the FOXG1/FOXO/ SMAD model of interacting proteins that are involved in controlling proliferation of neuroepithelial cells by acting on the Cdknla promoter. In the pathological case, this network is important in keeping glioblastoma cells in a proliferative state and in conferring escape from TGF $\beta$-mediated cytostasis. We discovered that FOXG1 expression impaired not only FOXO/SMAD-mediated cell cycle exit, but also TGF $\beta$-induced neuronal differentiation in a dose dependent manner at the developmental stage E13.5. Our in vitro data indicate that FOXO1 is an activator of Cdkn1a expression from E11.5 onwards, and that it is probably assisted by SMAD4 from E13.5 onwards (Figure 3 and 4). Our in vivo data do not indicate that TGF $\beta$-signaling via TGFBR2 or the neural ligands TGFB2 and 3 are essential regulators of $C d k n 1 a$ transcription. The reason might be that either FOXO1/ SMAD4-mediated Cdknla expression is only transient during the period when a progenitor leaves the cell cycle and enters neuronal differentiation. Alternatively, as our in vitro data indicate a robust SMAD4-dependent transcription of $C d k n 1 a$, SMAD-signals might be under control of alternative pathways, such as BMP or Activin. In addition, on the basis of our data we cannot rule out that other compensatory mechanisms, such as activation of TGF $\beta$-signaling in neural cells by increased levels of TGFB1, might cloud our analyses of the full impact of TGF $\beta$-signaling on Cdknla expression in vivo.

The FOXG1/FOXO/SMAD network was further characterized in the context of differentiation of Cajal-Retzius neurons [19]. Our data do not support the hypothesis that FOXG1 antagonizes a putative 


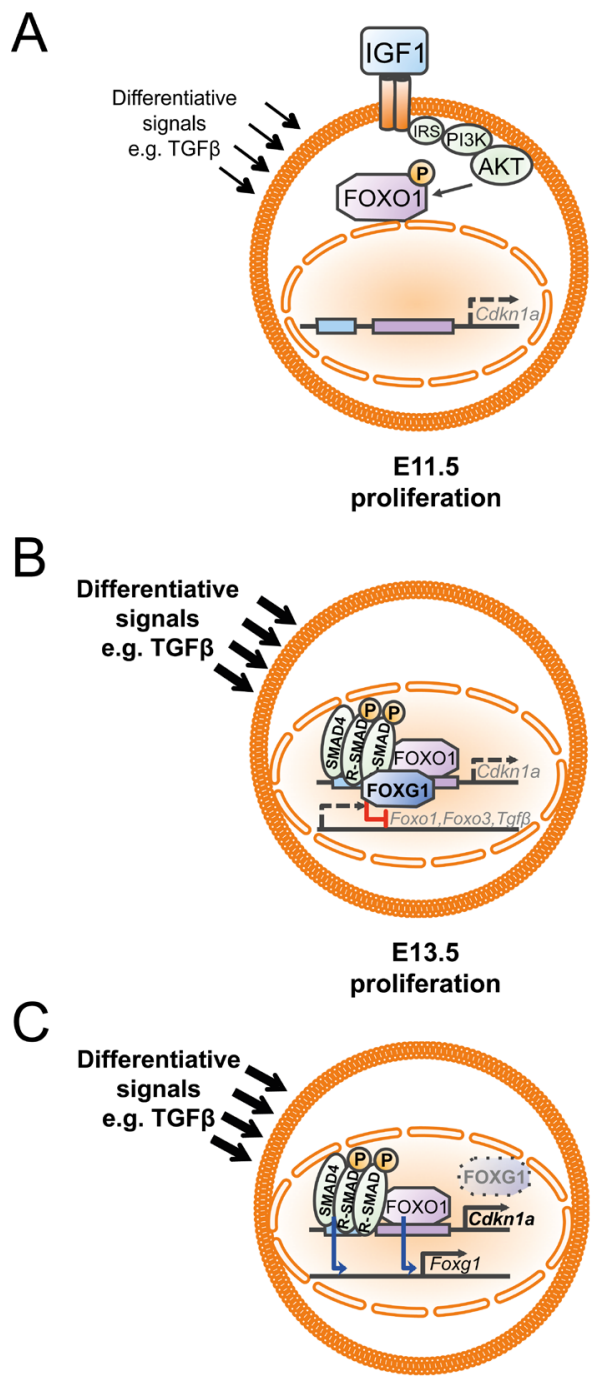

E13.5

differentiation

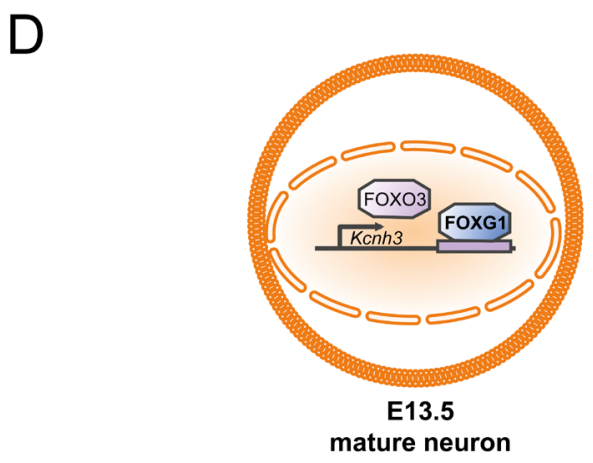

Figure 9: Developmental dynamics of the FOXG1/FOXO/SMAD4 network in the context of cortical progenitor proliferation and differentiation. A. At E11.5 proliferation is dominant and expression of Cdknla through FOXO1 protein is prevented by IGF1-mediated activation of the AKT-signaling pathway that keeps FOXO1 in the cytoplasm due to phosphorylation. B. As development progresses, progenitors are exposed to increasing amounts of differentiating signals. To prevent exit from mitosis FOXG1 associates with FOXO1 and SMAD4 complexes at the Cdknla promoter and thereby FOXG1 prevents cell cycle exit. At the same time, FOXG1 represses the expression of Foxo 1, Foxo3 and TgfB. C. In differentiating progenitors, transient downregulation of FOXG1 allows differentiating signals such as TGF $\beta$ to drive neuronal differentiation, which follows FOXO1/SMAD4 mediated transcription of Cdkn 1a. To allow differentiated cells to integrate into the cortical plate, FOXO1/SMAD4 proteins drive Foxg1 expression. D. FOXG1 binds to the 3'-UTR of Kcnh3 and activates expression of Kcnh3 in mature neurons. FOXO3 also drives Kcnh3 expression. 
involvement of TGF $\beta$-signals in the generation of CALB2positive CR cells from the PSB, as we revealed similar expression of CALB2 in Foxg1-/Tgfbr2-double deficient mice compared to FOXG1-deficient mice. However, we cannot rule out that SMAD4-dependent transcriptional regulation might promote $\mathrm{CR}$ differentiation, and that activation of SMAD4 occurs in response to BMP or Activin signals, independent of TGF $\beta$ ligands and receptors. Our additions to the existing model [7] show that the FOXG1/FOXO/SMAD transcriptional network acts in different complexes to confer different cellular responses depending on the developmental time point (Figure 9). In early developmental stages, such as E11.5, progenitors mainly proliferate. Under these conditions, IGF1-signaling secures the proliferating status by preventing FOXO1 translocation to the nucleus to drive Cdknla expression (Figure 9A, Figure 4, [2]). At E13.5 most progenitors still divide, but neuronal differentiation becomes increasingly important, and both proliferation and differentiation coexist. Thus, with progressing development, the progenitors are exposed to signals that increase neuronal differentiation although a subset of progenitors has to maintain the capacity for mitosis. As our data suggest, differentiating signals include TGF $\beta$. FOXG1-expressing progenitors stay in mitosis (Figure 9B) as FOXG1 associates with FOXO1 and SMAD complexes [7], blocks transcription of TgfB, Foxo1, Foxo3, and $C d k n 1 a$ (Figure 2, 3), binds to the Cdknla promoter (Figure 7) and hampers neuronal differentiation upon a TGF $\beta$-stimulus (Figure 1). Loss of FOXG1 (Figure 9C) renders progenitors capable to express $C d k n l a$ through FOXO1 and SMAD4 (Figure 2, 3) and to enter neuronal differentiation (Figure 1). Along this line, Miyoshi and Fishell [18] reported that transient downregulation of FOXG1 is needed in pyramidal neuron precursors to enter into the cortical plate. We show that FOXO1 and SMAD4 are strong candidates to drive the re-expression of Foxg1 in differentiating pyramidal neurons (Figure 3). Our finding that FOXG1 increases expression of Kcnh3 extends the view that FOXG1 has important functions in mature neurons beyond integration of pyramidal neurons into the cortical plate (Figure 9D).

Our data show that FOXG1 acts antagonistic to FOXO1 but along the same line as FOXO3. This reflects first of all non-redundant functions of the FOXO proteins, as FOXG1 opposes FOXO1-mediated transcription of Cdknla but drives Kcnh3 expression, which we also observed for FOXO3. It is possible that the position of the FOX-binding site determines the transcriptional readout. If the binding site is present at the 5' end it might be antagonistic ( $C d k n l a)$, while presence at the 3' end might be synergistic (Kcnh3). Our observation that FOXG1 increases $K c n h 3$ expression may also bear clinical relevance, as knockout mice for Kcnh3 show improved cognitive performance, enhanced spatial working memory and enhanced latent learning memory [32]. In addition,
Kcnh3-deficient mice show signs of persistent neuronal hyperexcitability including frequent interictal spiking and spontaneous seizures [34]. Early-onset seizures are also a specific feature of the pathology of atypical Rett syndrome, which is caused by FOXG1 haploinsufficiency in humans (FOXG1 syndrome, OMIM\#164874) [3542]. It is tempting to speculate that reduced expression of $\mathrm{KCNH} 3$ is involved in the pathology of the FOXG1syndrome in humans.

\section{CONCLUSIONS}

These data show that the FOXG1/FOXO/SMAD transcription factor network balances proliferation and differentiation in cortical progenitors. Our data strongly suggest that the network is dynamically involved in the control of cell cycle exit and neuronal differentiation. The network components are used differently while development progresses. Cdknla expression underlies IGF1-controlled interference of nuclear translocation of FOXO1 at E11.5, when neither TGF $\beta$ nor FOXG1 are strongly expressed. At later developmental stages Cdknla expression is prevented through FOXG1mediated interference with FOXO1/SMAD4. FOXO1/ SMAD4 complexes induce Foxg1 expression, which makes them candidates for resuming FOXG1 expression in differentiating cortical neurons, which have left mitosis after transient downregulation of FOXG1. FOXG1 and FOXO3 are of relevance to control expression of the seizure-related Kcnh3. FOXG1-mediated expression of ion channels could be relevant to understand the pathology of the FOXG1 syndrome, an autism spectrum disorder.

\section{MATERIALS AND METHODS}

\section{Mouse strains and genotyping}

Foxg1 $1^{-/-}, \quad$ Foxg $1^{\text {cre/+}} ;$ Tgfbr2 $2^{\text {flox/flox }}$ (Tgfbr2 cKO), Foxg $1^{\text {cre/cre }} ;$ Tgfbr $2^{\text {flox/flox }}$ (Foxg1;Tgfbr2 dKO) and Tgfb $2^{-/-}$ ; Tgfb3 ${ }^{-/}$(Tgfb2;Tgfb3 dKO) were obtained and genotyped as previously described [43-46]. B16N and NMRI mice were obtained from Charles River and Janvier. The animal welfare committee of the University of Freiburg and local authorities approved all animal experiments (registered license X11/09S and X14/04H). For genotyping, tails were lysed in QuickExtract DNA Extract Solution (Biozym Scientific GmbH, Hessisch Oldendorf, Germany) according to manufacturer's instructions. PCR was performed using Taq polymerase (Go-Taq, Promega, Fitchburg, WI, USA) and according to instructions the following primers (Invitrogen, Carlsbad, CA, USA; Sigma, St. Louis, MO, USA) were used:

Bf1_F25 GCCGCCCCCCGACGCCTGGGTGATG

Bf1_R159 TGGTGTGGTGATGATGATGATGGTGATGCTG 
Bf1 Rcre ATAATCGCGAACATCTTCAGGTTCTGGGGG

LaLox ACTTCTGCAAGAGGTCCCCT

8wa TAAACAAGGTCCGGAGCCCA

b2-3 AACTCCATAGATATGGGGATGC

b2 neo GCCGAGAAAGTATCCATCAT

b2-5 AATGTGCAGGATAATTGCTGC

\section{Primary cultures of mouse embryonic cortical cells}

Cortical cells were isolated from embryonic mice at various time points (E11.5, E13.5, E16.5), dissected in Hanks' Balanced Salt Solution (HBSS, PAA, Cölbe, Germany) and dissociated by trypsinization in $0.25 \%$ Trypsin-ethylenediaminetetracetic acid (PAA) at $37^{\circ} \mathrm{C}$ for $7 \mathrm{~min}$. Half a volume of Fetal Bovine Serum (FBS, Life Technologies) and one volume of Neurobasal (NB) complete medium supplemented with B27 (both from Life Technologies), apo-transferrin (5 $\mu \mathrm{g} / \mathrm{ml}$, Sigma), superoxide-dismutase $(0.8 \mu \mathrm{g} / \mathrm{ml}$, Sigma $)$, L-glutamine (0.5 mM, Life Technologies), PSN (Life Technologies), glutathione $(1 \mu \mathrm{g} / \mathrm{ml}$, Sigma) were added. Cells were triturated. DNase treatment (Roche, Basel, Switzerland) was performed to help the trituration process $(10 \mu \mathrm{g}$ DNAse per ml of trypsin). Cells were plated on polyornithine $(0.1 \mathrm{mg} / \mathrm{ml}$, Sigma, München, Germany) and laminin $(1 \mu \mathrm{g} / \mathrm{ml}$, Sigma) coated dishes at a density of $100000 \mathrm{cells} / \mathrm{cm}^{2}$. The day of the plating was considered DIV0. Cells were harvested on different days ranging from DIV4 to DIV9. For the possible treatment schemes, based on the performed experiments, see Figure S4. For immunocytochemistry, TGFB1 $(5 \mathrm{ng} / \mathrm{ml})$ was applied at DIV2 or DIV3, according to experimental need.

\section{Production of lentiviral particles}

Lentiviral particles were produced and their titer determined as previously described [45]. Briefly, HEK293T cells were transfected with Mirus TransIT-293 Transfection Reagent (Mirus Bio LLC, Madison, WI, USA) following manufacturer's instructions. The following plasmid concentrations were used for one 10cm dish: $2.4 \mu \mathrm{g}$ psPax $2 ; 2.4 \mu \mathrm{g}$ pMD.2-VSVG; $4.8 \mu \mathrm{g}$ Vector plasmid. Medium was harvested after $72 \mathrm{~h}$ posttransfection, pre-cleared by centrifugation and filtered through a $0.45 \mu \mathrm{m}$ filter. The viral particles were pelleted by ultracentrifugation $\left(25000 \mathrm{rpm}\right.$ for $2 \mathrm{~h}$ at $\left.4^{\circ} \mathrm{C}\right)$. The viral pellet was resuspended in NB complete medium. Titer was determined by a qRTPCR-based approach.

\section{Infection with lentiviral particles}

Cells were infected on DIV1 with 1.25 infecting units (IFU)/cell (shRNA-mediated knockdown) or $10 \mathrm{IFU/}$ cell (Cdknla overexpression). The following constructs were used for shRNA-mediated knockdown: shFoxg1
TRCN0000081746 (CCTGACGCTCAATGGCATCTA), shFoxo1 TRCN0000234399 (TGGAAACCAGCCAGCTA TAAA), shFoxo3 TRCN0000312843 (CAGCCGTGCC TTGTCAAATTC) in pLKO.1-puro-CMVtGFP backbone (all purchased from Sigma). The coding region of Cdknla (forward primer: GGAATTCCCACCATGTCCAATCCTGGTGATGTC; reverse primer: CGCGGATCCGCGGGGTTTTCTC TTGCAGAAGAC) was cloned into a pLenti-III-2AmCherry-nopuro backbone (Applied Biological Materials Inc., Richmond, BC, Canada) for overexpression. Selection of successfully infected cells was performed 72$90 \mathrm{~h}$ post-infection (DIV4) by changing the medium to NB complete medium with $0.3 \mu \mathrm{g} / \mathrm{ml}$ puromycin (Sigma) for 3 days. For harvesting schedule see Figure S4.

RNA isolation, reverse transcription, and quantitative real-time PCR (qPCR) and qRTPCR data analysis

Total RNA was isolated from the harvested cells and frozen tissue using RNeasy mini kit (Qiagen, Germany) according to the manufacturer's instructions including DNA digestion. One $\mu \mathrm{g}$ of total RNA was reverse transcribed with RevertAid MMuLV (Fermentas, Thermo Scientific) according to instructions.

Quantitative real-time RT-PCR analysis was performed on a Bio-Rad MyIQ Single-Color or CFXConnect Real-Time PCR detection system (Bio-Rad, München, Germany) using Go Taq qPCR Master Mix (Promega, Mannheim, Germany). Primers were used at a concentration of $250 \mathrm{nM}$ each. Gapdh was used as the reference gene. Following PCR program was used: $3 \mathrm{~min}$ at $95^{\circ} \mathrm{C}, 40$ cycles of 15 seconds $95^{\circ} \mathrm{C}$ followed by $1 \mathrm{~min}$ $15 \mathrm{sec}$ at an annealing temperature $\left(58^{\circ} \mathrm{C}-63^{\circ} \mathrm{C}\right), 1 \mathrm{~min}$ $95^{\circ} \mathrm{C}, 1 \mathrm{~min} 55^{\circ} \mathrm{C}$ and melting curve cycle. Used primers had an efficiency level between $85 \%$ and $110 \%$. Primer sequences are listed in Table S2.

qRTPCR results were analyzed using the $\Delta \Delta \mathrm{Ct}$ method [47]. Results were shown as fold change or $\log _{2}$ (fold change). The error bar was calculated based on the law of error propagation as previously described [45].

Viral RNA was isolated in RNAse-free conditions using a modified version of the protocol devised by Murdoch et al. [48]. Viral suspension was lysed using TRIzol reagent (Life Technologies). After adding $20 \mu \mathrm{g}$ of glycogen (Peqlab, Erlangen, Germany) and bringing the suspension to a volume of $300 \mu \mathrm{l}, 900 \mu \mathrm{l}$ of TRIzol reagent followed by $240 \mu \mathrm{l}$ of chloroform (Sigma) were added to the mix. Subsequent extraction and purification steps were carried out as originally stated [48]. $10 \mu \mathrm{l}$ of the viral RNA were reverse transcribed, while other 10 $\mu \mathrm{l}$ were used for a mock-RT. RT and mock-RT products were diluted at least 1:10 and were used for qRTPCR using primers amplifying the $\Psi$ packaging sequence. After 
setting up a standard curve, an absolute quantification was carried out.

The following formula was used to determine the concentration of lentiviral particles (expressed as LP/ml):

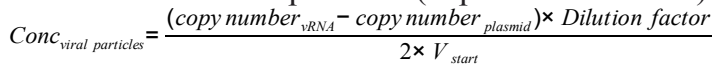

Where copy number ${ }_{v R N A}$ is defined as the amount of vRNA determined from the reverse transcribed samples, copy number ${ }_{\text {plasmid }}$ is the amount of plasmidic DNA carried over after transfection (determined from the mock-RT) and $V_{\text {start }}$ is the amount of viral suspension used for the quantification. We defined an IFU as 100 LP. The primers used are listed in Table S2.

\section{Gene expression profiling}

Gene expression profiles of Foxg $1^{-/-}$mice $(n=3)$ and wild-type control mice $(n=2)$ were analyzed using Agilent's Whole Mouse Genome Microarray (026655). CPCs from E13.5 embryos were treated with ALK4,5,7inhibitor SB431542 $(10 \mu \mathrm{M})$ on DIV2 and on DIV3 treated with TGFB1 $(5 \mathrm{ng} / \mathrm{ml})$. CPCs were collected on DIV4 and total RNA was extracted and processed as described. See Figure S4 for a concise treatment scheme. Cy3 intensities were detected by one-color scanning using an "Agilent DNA Microarray Scanner (G250B)" at $5 \mu \mathrm{m}$ resolution.

\section{Microarray data analysis}

Intensity data were extracted using Agilent's Feature Extraction (FE) software (version 9.5.3.1) including a quality control based on internal controls using Agilent's protocol GE1107 Sep09. Microarray data analysis consists of the following steps: 1. between-array normalization, 2 . global clustering and PCA-analysis, 3 . fitting the data to a linear model, 4. detection of differential gene expression and 5. over-representation analysis of differentially expressed genes. To estimate the average group values for each gene and assess differential gene expression, a simple linear model was fitted to the data, and groupvalue averages and standard deviations for each gene were obtained. To find genes with significant expression changes between groups, empirical Bayes statistics were applied to the data by moderating the standard errors of the estimated values [49]. P-values were obtained from the moderated t-statistic and corrected for multiple testing with the Benjamini-Hochberg method [50]. For each gene, the null hypothesis, that there is no differential expression between degradation levels, was rejected when its false discovery rate was lower than 0.05 . To find overrepresented functions (as represented by Gene Ontology terms) [51], we used DAVID, the Database for Annotation, Visualization and Integrated Discovery [26, 27].

\section{Immunoblotting}

The procedure was carried out as previously described [45]. Briefly, tissue or cultured CPCs were lysed in RIPA buffer (1\% NP-40, $1 \%$ SDS, $0.5 \%$ sodium deoxycholate diluted in Phosphate Buffered Saline, PBS) supplemented with protease inhibitor (cOmplete Protease Inhibitor Cocktail, Roche) and sonicated for 10 cycles of $10 \mathrm{sec}$ sonication and $10 \mathrm{sec}$ pause with the Bioruptor Next Gen Sys (Diagenode, Seraing, Belgium). After centrifugation (10 $\mathrm{min}, 13000 \mathrm{rpm}$ ) the supernatant was collected. Protein concentrations were determined with Bradford reagent (Bio-Rad). $15 \mu \mathrm{g}$ of protein extract were loaded with $5 \mathrm{x}$ Laemmli buffer on Mini Protean TGX gels (Bio-Rad) and run at 100V for $1.5 \mathrm{~h}$. Proteins were transferred to PVDF membranes (Trans-blot Turbo Transfer Pack) using the Trans-blot Turbo Transfer System (both from Bio-Rad) following the manufacturer's instructions. Membranes were blocked with 5\% BSA in TBS-T (blocking buffer) for $1 \mathrm{~h}$ and incubated overnight with primary antibodies (diluted in blocking buffer). Membranes were washed, incubated with secondary antibodies for $1 \mathrm{~h}$ and detected using ECL or Femto substrates (Thermo Scientific) and LAS ImageQuant System (GE Healthcare, Little Chalfont, UK).

The following antibodies were used: anti-FOXG1 (1:1000 dilution; \#18529) and GAPDH (1:3000 dilution; \#8245), from Abcam. For densitometric analyses, ImageJ software was used [52].

\section{Immunohistochemistry (IHC) and immunocytochemistry (ICC)}

IHC was performed on fixed forebrains (4\% PFA) embedded in Tissue Freezing Medium (Leica biosystems, Wetzlar, Germany) and cut into $12 \mu \mathrm{m}$ section. Prior to their use, sections were thawed for $10 \mathrm{~min}$ at $37^{\circ} \mathrm{C}$ and subsequently postfixed for $30 \mathrm{~min}$. Permeabilization was performed in either $0.1 \%$ or $1 \%$ Triton X/PBS for $30 \mathrm{~min}$. After $1 \mathrm{~h}$ of blocking in 5\% BSA/PBS (Roth, Karlsruhe, Germany) or in $1 \% \mathrm{BSA} / 4 \%$ donkey serum $/ 1 \%$ normal goat serum (NGS) $/ 0.1 \%$ Triton X/PBS, sections were incubated with primary antibody against CALB2 (\#92341, $1: 100$ in $1 \%$ BSA/PBS, Abcam) or FOXG1 (\#18529, $1: 500$ in $1 \% \mathrm{BSA} / 4 \%$ donkey serum $/ 1 \% \mathrm{NGS} / 0.1 \%$ Triton $\mathrm{X} / \mathrm{PBS}, \mathrm{Abcam}$ ), respectively. On the next day, secondary antibody was applied for $1 \mathrm{~h}$ at RT. Sections were then counterstained with 1:1000 4',6-diamidino-2-phenylindole (DAPI) solution and embedded in Fluorescent Mounting Medium (DAKO, Jena, Germany).

For ICC, cells plated on coverslips were fixed for 20 min with $4 \%$ PFA and permeabilized in acetone for $10 \mathrm{~min}$ at $-20^{\circ} \mathrm{C}$. Blocking was performed in $10 \%$ normal goat serum, $1 \%$ Triton X/PBS for $1 \mathrm{~h}$ at RT, followed by the incubation with primary antibodies in blocking solution at 
$4^{\circ} \mathrm{C}$ overnight. The incubation with secondary antibodies was carried out for $1 \mathrm{~h}$ at RT, followed by counterstaining with DAPI (1:1000) and mounting in Fluorescent Mounting Medium (DAKO). The following antibodies were used: Anti-HuC/D antibody \#A-21271, 1:100 (Life Technologies), FOXO3 \#47409, 1:500 (Abcam). All secondary antibodies were purchased from Invitrogen.

Images were taken with Axioplan 2, Axio Imager M2 with or without ApoTome 2.0 (Zeiss, Jena, Germany). Positive cells were counted manually using ImageJ software [52]. For each condition, at least 947 total cells were counted.

\section{Chromatin immunoprecipitation}

The procedure was carried out as previously described [53] with some modifications. CPCs were fixed with $1 \%$ freshly prepared PFA (Roth) for $5 \mathrm{~min}$ at RT. The cross-link was stopped by addition of glycine to a final concentration of $125 \mathrm{mM}$. Cells were washed twice with PBS and lysed in DNA lysis buffer (50 mM TRIS$\mathrm{HCl}$, pH 8.0, 10 mM EDTA, 0.1\% SDS) supplemented with protease inhibitor (Roche). Chromatin was sheared within 30 high-energy cycles by the Bioruptor Next Gen System (Diagenode): $30 \mathrm{~s}$ on and $30 \mathrm{~s}$ off to achieve DNA fragment lengths between 200-600 bp. The chromatin concentration was quantified with the NanoDrop 2000 (Thermo Scientfic), diluted in DNA dilution buffer (20 mM TRIS-HCl, pH 8.0, $150 \mathrm{mM} \mathrm{NaCl}, 2 \mathrm{mM}$ EDTA, 1\% Triton X-100) supplemented with protease inhibitor (Roche), bovine serum albumin in PBS (final concentration: $0.1 \%$ ) and precleared using Protein A Dynabeads (Life Technologies) for $2 \mathrm{~h}$ at $4^{\circ} \mathrm{C}$. Antibodies were bound to equilibrated Protein A Dynabeads for $2 \mathrm{~h}$ at $4^{\circ} \mathrm{C}$. Precleared supernatants were then added to antibody-bound beads. For immunoprecipitation, 20$30 \mu \mathrm{g}$ of chromatin were incubated either with antibody directed against FOXG1 (1 $\mu \mathrm{g}$ per $20 \mu \mathrm{g}$ chromatin; \#18529, Abcam) or rabbit $\operatorname{IgG}(1.3 \mu \mathrm{g}$ per $20 \mu \mathrm{g}$ chromatin; \#C15410206, Diagenode) at $4^{\circ} \mathrm{C}$ overnight. Immunocomplexes were washed for $10 \mathrm{~min}$ once with buffer 1 (20 mM TRIS-HCl, pH 8.0, $150 \mathrm{mM} \mathrm{NaCl,} 2$ mM EDTA, 1\% Triton X-100, 0.2\% SDS), buffer 2 (20 mM TRIS-HCl, pH 8.0, 500 mM NaCl, 2 mM EDTA, 1\% Triton X-100, 0.2\% SDS), buffer 3 (20 mM TRIS-HCl, pH 8.0, $250 \mathrm{mM} \mathrm{LiCl,} 2 \mathrm{mM}$ EDTA, 1\% NP-40, 1\% sodium deoxycholate) and thrice with TE buffer (20 mM TRIS$\mathrm{HCl}, \mathrm{pH} 8.0,2 \mathrm{mM}$ EDTA) at $4{ }^{\circ} \mathrm{C}$. DNA was extracted from beads in extraction buffer (1\% SDS / $100 \mathrm{mM}$ $\mathrm{NaHCO}_{3}$ ) by shaking at $1400 \mathrm{rpm}$ at RT for $1 \mathrm{~h}$. ChIP and input DNA samples were incubated with RNase A (Sigma) at $37^{\circ} \mathrm{C}$ for $30 \mathrm{~min}$, followed by the Proteinase $\mathrm{K}$ (Roche) digestion at $65^{\circ} \mathrm{C}$ while shaking at $1400 \mathrm{rpm}$ for $6 \mathrm{~h}$ during the removal of the cross-link. Purification of the ChIP and input DNA samples was done following the instructions provided by the manufacturer of the MinElute Reaction Cleanup Kit and PCR purification Kit (both Qiagen), respectively. All DNA samples were diluted accordingly, quantified fluorospectroscopically using the Quanti-iTPicoGreen dsDNA Assay Reagent (Life Technologies) and the NanoDrop 3300 (Thermo-Scientific). To analyze the enrichment of the ChIP samples, a qPCR was performed. 20 to 320 pg of DNA was applied per reaction. $\mathrm{Ct}$ values of ChIP samples were normalized to $\mathrm{Ct}$ values of input to calculate enrichment (\% input). Final results are shown as a ratio between FOXG1 enrichment at a specific site and its enrichment in a region devoid of FOX binding sites, which was used as a negative control.

\section{Riboprobe synthesis and in-situ hybridization}

This experiment was performed as previously described [54] with some modifications. Briefly, PCR products using Kcnh3 primers (forward: CAGCTTTATGGACCTCCACTTC; reverse: AGAGCCTGTGGATCTCTAGCC, Allen Brain Atlas [55, 56]) were cloned into the pGEM-T Easy Vector System (Promega) according to manufacturer's instructions. The cloning product was linearized through digestion with NcoI (sense probe) or SacI (antisense probe) and transcribed with SP6- or T7-RNA polymerases (Roche), respectively. Forebrain slices were hybridized with digoxigenin-labelled riboprobes in hybridization buffer (12.7 mM Tris base, $184.4 \mathrm{mM} \mathrm{NaCl}, 5.9 \mathrm{mM} \mathrm{NaH}_{2} \mathrm{PO}_{4}$, $6.27 \mathrm{mM} \mathrm{Na}_{2} \mathrm{HPO}_{4}, 5 \mathrm{mM}$ EDTA pH 8.0, 0.5x Denhardt's solution, $1 \mathrm{mg} / \mathrm{ml}$ Yeast RNA, 10\% Dextran sulfate, 50\% v/v Formamide) at $68^{\circ} \mathrm{C}$ overnight. Sections were washed thrice in a solution containing $50 \%$ formamide, $0.1 \%$ Tween-20 and $5 \%$ saline sodium citrate at $68^{\circ} \mathrm{C}$ in a water bath. They were then transferred to an incubation chamber and washed twice with maleic acid buffer and Tween-20 (MABT) for $30 \mathrm{~min}$ at RT. After blocking in a MABT solution containing 20\% lamb serum, sections were incubated with an alkaline phosphatase-conjugated antidigoxigenin antibody (1:1500 in blocking solution; Roche) overnight at RT. After four washing steps in MABT (10 min, 3x $20 \mathrm{~min}$ ) and three washing steps (7 min each) in pre-staining buffer, the reaction product was developed using NBT/BCIP solution diluted in pre-staining buffer (1:100; Roche) overnight at RT. Stained sections were washed 4 times in PBS and then embedded using Aquatex (Merck Millipore). Image acquisition was performed using an Axio Imager 2 microscope without apotome (Zeiss). 


\section{Statistical analysis}

Unpaired Student's $t$-test was used for all qRTPCR experiments where mutant values were compared with their respective controls and, in general, when comparison was performed between two groups. One-way ANOVA with either Šidák's, Dunnet's or Tukey's post-test was used in experiments involving comparison among more than one group. Analysis of experiments involving cell infection with lentiviral shRNA constructs and ChIP was performed using One-sample $t$-test, where comparison was made between each value and the control value (set as 0 ). Values in bar charts are expressed as average \pm SEM.

\section{ACKNOWLEDGMENTS}

The authors thank the DNA Microarray and Deep-Sequencing Facility Göttingen for performing the microarray hybridization; L. Opitz for analyzing the microarray results; M. Löffler, U. Baur and A. Marchewka for technical support, and J. Davis for contributing to manuscript editing.

\section{CONFLICTS OF INTEREST}

The authors declare that there is no conflict of interest.

\section{GRANT SUPPORT}

This work was funded by a grant of Deutsche Forschungsgemeinschaft (grant number VO1676/11 to TV). SCW is a member of the Deutsche Forschungsgemeinschaft Graduiertenkolleg 1104.

\section{Authors' contributions}

RV performed the experiments, analyzed the results and was involved in manuscript writing and revision. SCW contributed to the experiments, analyzed results and was involved in manuscript writing and revision. $\mathrm{NH}$ contributed to the experiments, analyzed results and was involved in manuscript writing. VM and SH contributed to the experiments. TV conceived the study, participated in its design, analyzed results, interpreted data and wrote the manuscript.

\section{REFERENCES}

1. Vogel T, Ahrens S, Büttner N, Krieglstein K. Transforming growth factor beta promotes neuronal cell fate of mouse cortical and hippocampal progenitors in vitro and in vivo: identification of Nedd9 as an essential signaling component. Cereb Cortex. 2010; 20:661-71. doi: 10.1093/cercor/ bhp 134.

2. Wahane SD, Hellbach N, Prentzell MT, Weise SC, Vezzali R, Kreutz C, Timmer J, Krieglstein K, Thedieck K, Vogel T. PI3K-p110-alpha-subtype signalling mediates survival, proliferation and neurogenesis of cortical progenitor cells via activation of mTORC2. J Neurochem. 2014; 130:25567. doi: 10.1111/jnc. 12718 .

3. Derynck R, Zhang YE. Smad-dependent and Smadindependent pathways in TGF-beta family signalling. Nature. 2003; 425:577-84. doi: 10.1038/nature02006.

4. Dünker N, Krieglstein $\mathrm{K}$. Targeted mutations of transforming growth factor-beta genes reveal important roles in mouse development and adult homeostasis. Eur $\mathbf{J}$ Biochem. 2000; 267:6982-8.

5. Massagué J. TGFbeta in Cancer. Cell. 2008; 134:215-30. doi: 10.1016/j.cell.2008.07.001.

6. ten Dijke P, Arthur HM. Extracellular control of TGFbeta signalling in vascular development and disease. Nat Rev Mol Cell Biol. 2007; 8:857-69. doi: 10.1038/nrm2262.

7. Seoane J, Le H-V, Shen L, Anderson SA, Massagué J. Integration of Smad and forkhead pathways in the control of neuroepithelial and glioblastoma cell proliferation. Cell. 2004; 117:211-23.

8. Siegenthaler JA, Miller MW. Transforming growth factor beta 1 promotes cell cycle exit through the cyclindependent kinase inhibitor $\mathrm{p} 21$ in the developing cerebral cortex. J Neurosci. 2005; 25:8627-36. doi: 10.1523/ JNEUROSCI.1876-05.2005.

9. Alexandrow MG, Moses HL. Transforming growth factor beta and cell cycle regulation. Cancer Res. 1995; 55:14527.

10. Kang Y, Chen C-R, Massagué J. A self-enabling TGFbeta response coupled to stress signaling: Smad engages stress response factor ATF3 for Id1 repression in epithelial cells. Mol Cell. 2003; 11:915-26.

11. Siegel PM, Massagué J. Cytostatic and apoptotic actions of TGF-beta in homeostasis and cancer. Nat Rev Cancer. 2003; 3:807-21. doi: 10.1038/nrc1208.

12. Brunet A, Bonni A, Zigmond MJ, Lin MZ, Juo P, Hu LS, Anderson MJ, Arden KC, Blenis J, Greenberg ME. Akt promotes cell survival by phosphorylating and inhibiting a Forkhead transcription factor. Cell. 1999; 96:857-68.

13. Dou C, Lee J, Liu B, Liu F, Massague J, Xuan S, Lai E. BF-1 interferes with transforming growth factor beta signaling by associating with Smad partners. Mol Cell Biol. 2000; 20:6201-11.

14. Xuan S, Baptista CA, Balas G, Tao W, Soares VC, Lai E. Winged helix transcription factor BF-1 is essential for the development of the cerebral hemispheres. Neuron. 1995; 14:1141-52.

15. Brancaccio M, Pivetta C, Granzotto M, Filippis C, Mallamaci A. Emx2 and Foxg1 inhibit gliogenesis and promote neuronogenesis. Stem Cells. 2010; 28:1206-18. doi: $10.1002 /$ stem. 443 . 
16. Hanashima C, Shen L, Li SC, Lai E. Brain factor-1 controls the proliferation and differentiation of neocortical progenitor cells through independent mechanisms. J Neurosci. 2002; 22:6526-36. doi: 20026494.

17. Ahlgren S, Vogt P, Bronner-Fraser M. Excess FoxG1 causes overgrowth of the neural tube. J Neurobiol. 2003; 57:337-49. doi: 10.1002/neu.10287.

18. Miyoshi G, Fishell G. Dynamic FoxG1 expression coordinates the integration of multipolar pyramidal neuron precursors into the cortical plate. Neuron. 2012; 74:104558. doi: 10.1016/j.neuron.2012.04.025.

19. Siegenthaler JA, Miller MW. Generation of Cajal-Retzius neurons in mouse forebrain is regulated by transforming growth factor beta-Fox signaling pathways. Dev Biol. 2008; 313:35-46. doi: 10.1016/j.ydbio.2007.09.036.

20. Hevner RF, Neogi T, Englund C, Daza RAM, Fink A. Cajal-Retzius cells in the mouse: transcription factors, neurotransmitters, and birthdays suggest a pallial origin. Brain Res Dev Brain Res. 2003; 141:39-53.

21. Bielle F, Griveau A, Narboux-Nême N, Vigneau S, Sigrist M, Arber S, Wassef M, Pierani A. Multiple origins of CajalRetzius cells at the borders of the developing pallium. Nat Neurosci. 2005; 8:1002-12. doi: 10.1038/nn1511.

22. Takiguchi-Hayashi K, Sekiguchi M, Ashigaki S, Takamatsu M, Hasegawa H, Suzuki-Migishima R, Yokoyama M, Nakanishi S, Tanabe Y. Generation of reelin-positive marginal zone cells from the caudomedial wall of telencephalic vesicles. J Neurosci. 2004; 24:2286-95. doi: 10.1523/JNEUROSCI.4671-03.2004.

23. Tole S, Patterson PH. Regionalization of the developing forebrain: a comparison of FORSE-1, Dlx-2, and BF-1. J Neurosci. 1995; 15:970-80.

24. Martynoga B, Morrison H, Price DJ, Mason JO. Foxg1 is required for specification of ventral telencephalon and region-specific regulation of dorsal telencephalic precursor proliferation and apoptosis. Dev Biol. 2005; 283:113-27. doi: 10.1016/j.ydbio.2005.04.005.

25. Siegenthaler JA, Tremper-Wells BA, Miller MW. Foxg1 haploinsufficiency reduces the population of cortical intermediate progenitor cells: effect of increased p21 expression. Cereb Cortex. 2008; 18:1865-75. doi: 10.1093/ cercor/bhm209.

26. Huang DW, Sherman BT, Lempicki RA. Systematic and integrative analysis of large gene lists using DAVID bioinformatics resources. Nat Protoc. 2009; 4:44-57. doi: 10.1038/nprot.2008.211

27. Huang DW, Sherman BT, Lempicki RA. Bioinformatics enrichment tools: paths toward the comprehensive functional analysis of large gene lists. Nucleic Acids Res. 2009; 37:1-13. doi: 10.1093/nar/gkn923.

28. Flanders KC, Lüdecke G, Engels S, Cissel DS, Roberts $\mathrm{AB}$, Kondaiah P, Lafyatis R, Sporn MB, Unsicker K. Localization and actions of transforming growth factor-beta $\mathrm{S}$ in the embryonic nervous system. Development. 1991;
113:183-91.

29. Brownawell AM, Kops GJ, Macara IG, Burgering BM. Inhibition of nuclear import by protein kinase B (Akt) regulates the subcellular distribution and activity of the forkhead transcription factor AFX. Mol Cell Biol. 2001; 21:3534-46. doi: 10.1128/MCB.21.10.3534-3546.2001.

30. Mahmud DL, G-Amlak M, Deb DK, Platanias LC, Uddin S, Wickrema A. Phosphorylation of forkhead transcription factors by erythropoietin and stem cell factor prevents acetylation and their interaction with coactivator p300 in erythroid progenitor cells. Oncogene. 2002; 21:1556-62. doi: 10.1038/sj.onc. 1205230 .

31. Silvestri C, Narimatsu M, von Both I, Liu Y, Tan NBJ, Izzi L, McCaffery P, Wrana JL, Attisano L. Genomewide identification of Smad/Foxh1 targets reveals a role for Foxh1 in retinoic acid regulation and forebrain development. Dev Cell. 2008; 14:411-23. doi: 10.1016/j. devcel.2008.01.004.

32. Miyake A, Mochizuki S, Yokoi H, Kohda M, Furuichi K. New ether-à-go-go $\mathrm{K}(+)$ channel family members localized in human telencephalon. J Biol Chem. 1999; 274:25018-25.

33. Broos S, Hulpiau P, Galle J, Hooghe B, Van Roy F, De Bleser P. ConTra v2: a tool to identify transcription factor binding sites across species, update 2011. Nucleic Acids Res. 2011; 39:W74-78. doi: 10.1093/nar/gkr355.

34. Zhang X, Bertaso F, Yoo JW, Baumgärtel K, Clancy SM, Lee V, Cienfuegos C, Wilmot C, Avis J, Hunyh T, Daguia C, Schmedt C, Noebels J, et al. Deletion of the potassium channel Kv12.2 causes hippocampal hyperexcitability and epilepsy. Nat Neurosci. 2010; 13:1056-8. doi: 10.1038/ nn.2610.

35. Rolando S. Rett syndrome: report of eight cases. Brain Dev. 1985; 7:290-6.

36. Ariani F, Hayek G, Rondinella D, Artuso R, Mencarelli MA, Spanhol-Rosseto A, Pollazzon M, Buoni S, Spiga O, Ricciardi S, Meloni I, Longo I, Mari F, et al. FOXG1 is responsible for the congenital variant of Rett syndrome. Am J Hum Genet. 2008; 83:89-93. doi: 10.1016/j. ajhg.2008.05.015.

37. Neul JL, Kaufmann WE, Glaze DG, Christodoulou J, Clarke AJ, Bahi-Buisson N, Leonard H, Bailey MES, Schanen NC, Zappella M, Renieri A, Huppke P, Percy AK, et al. Rett syndrome: revised diagnostic criteria and nomenclature. Ann Neurol. 2010; 68:944-50. doi: 10.1002/ana.22124.

38. De Filippis R, Pancrazi L, Bjørgo K, Rosseto A, Kleefstra T, Grillo E, Panighini A, Cardarelli F, Meloni I, Ariani F, Mencarelli MA, Hayek J, Renieri A, et al. Expanding the phenotype associated with FOXG1 mutations and in vivo FoxG1 chromatin-binding dynamics. Clin Genet. 2012; 82:395-403. doi: 10.1111/j.1399-0004.2011.01810.x.

39. Kumakura A, Takahashi S, Okajima K, Hata D. A haploinsufficiency of FOXG1 identified in a boy with congenital variant of Rett syndrome. Brain Dev. 2014; 36:725-9. doi: 10.1016/j.braindev.2013.09.006. 
40. Papa FT, Mencarelli MA, Caselli R, Katzaki E, Sampieri K, Meloni I, Ariani F, Longo I, Maggio A, Balestri P, Grosso S, Farnetani MA, Berardi R, et al. A 3 Mb deletion in $14 \mathrm{q} 12$ causes severe mental retardation, mild facial dysmorphisms and Rett-like features. Am J Med Genet A. 2008; 146A:1994-8. doi: 10.1002/ajmg.a.32413.

41. Shoichet SA, Kunde S-A, Viertel P, Schell-Apacik C, von Voss H, Tommerup N, Ropers H-H, Kalscheuer VM. Haploinsufficiency of novel FOXG1B variants in a patient with severe mental retardation, brain malformations and microcephaly. Hum Genet. 2005; 117:536-44. doi: 10.1007/s00439-005-1310-3.

42. Jacob FD, Ramaswamy V, Andersen J, Bolduc FV. Atypical Rett syndrome with selective FOXG1 deletion detected by comparative genomic hybridization: case report and review of literature. Eur J Hum Genet. 2009; 17:1577-81. doi: 10.1038/ejhg.2009.95.

43. Hébert JM, McConnell SK. Targeting of cre to the Foxg1 (BF-1) Locus Mediates loxP Recombination in the Telencephalon and Other Developing Head Structures. Dev Biol. 2000; 222:296-306. doi: 10.1006/dbio.2000.9732.

44. Chytil A, Magnuson MA, Wright CVE, Moses HL. Conditional inactivation of the TGF- $\beta$ type II receptor using Cre:Lox. Genesis. 2002; 32:73-5. doi: 10.1002/gene.10046.

45. Hellbach N, Weise SC, Vezzali R, Wahane SD, Heidrich S, Roidl D, Pruszak J, Esser JS, Vogel T. Neural deletion of Tgfbr2 impairs angiogenesis through an altered secretome. Hum Mol Genet. 2014; 23:6177-90. doi: 10.1093/hmg/ ddu338.

46. Roussa E, Wiehle M, Dünker N, Becker-Katins S, Oehlke $\mathrm{O}$, Krieglstein K. Transforming growth factor beta is required for differentiation of mouse mesencephalic progenitors into dopaminergic neurons in vitro and in vivo: ectopic induction in dorsal mesencephalon. Stem Cells. 2006; 24:2120-9. doi: 10.1634/stemcells.2005-0514.

47. Livak KJ, Schmittgen TD. Analysis of relative gene expression data using real-time quantitative PCR and the 2(-Delta Delta C(T)) Method. Methods. 2001; 25:402-8. doi: 10.1006/meth.2001.1262.

48. Murdoch B, Pereira DS, Wu X, Dick JE, Ellis J. A rapid screening procedure for the identification of high-titer retrovirus packaging clones. Gene Ther. 1997; 4:744-9. doi: 10.1038/sj.gt.3300448.

49. Smyth GK. Linear models and empirical bayes methods for assessing differential expression in microarray experiments. Stat Appl Genet Mol Biol. 2004; 3:Article3. doi: 10.2202/1544-6115.1027.

50. Benjamini Y, Hochberg Y. Controlling the False Discovery Rate: A Practical and Powerful Approach to Multiple Testing. J Roy Statist Soc Ser B. 1995; 57:289-300.

51. Beissbarth T, Speed TP. GOstat: find statistically overrepresented Gene Ontologies within a group of genes. Bioinformatics. 2004; 20:1464-5. doi: 10.1093/ bioinformatics/bth088.

52. Abramoff MD, Magalhães PJ, Ram SJ. Image processing with ImageJ. Biophotonics Int. 2004; 11:36-42.

53. Roidl D, Hellbach N, Bovio PP, Villarreal A, Heidrich S, Nestel S, Grüning BA, Boenisch U, Vogel T. DOT1L Activity Promotes Proliferation and Protects Cortical Neural Stem Cells from Activation of ATF4-DDIT3-Mediated ER Stress In Vitro. Stem Cells. 2016; 34:233-45. doi: 10.1002/ stem.2187.

54. Zechel S, Huber-Wittmer K, von Bohlen und Halbach O. Distribution of the iron-regulating protein hepcidin in the murine central nervous system. J Neurosci Res. 2006; 84:790-800. doi: 10.1002/jnr.20991.

55. Lein ES, Hawrylycz MJ, Ao N, Ayres M, Bensinger A, Bernard A, Boe AF, Boguski MS, Brockway KS, Byrnes EJ, Chen L, Chen L, Chen T-M, et al. Genome-wide atlas of gene expression in the adult mouse brain. Nature. 2007; 445:168-76. doi: 10.1038/nature05453.

56. Gene Detail :: Allen Brain Atlas: Mouse Brain. Available from: http://mouse.brain-map.org/gene/show/16285. 